\title{
Biochemical and Molecular Characterization of Parents and its Crosses for High Oleic Acid Content in Sunflower (Helianthus annuus L.)
}

\author{
I.S. Tilak ${ }^{1 *}$, B. Kisan ${ }^{1}$, I. Shanker Goud ${ }^{2}$, Mahantesha B.N. Naika ${ }^{3}$, Ayyangouda Patil ${ }^{1}$, \\ Vikas Kulkarni $^{2}$, Kadirvel Palchamy ${ }^{4}$ and Praduman Yadav ${ }^{4}$
}

${ }^{1}$ Department of Molecular Biology and Agricultural Biotechnology, College of Agriculture, University of Agricultural Sciences, Raichur-584-104, Karnataka, India

${ }^{2}$ All India Co-ordinated Research Project on Sunflower, Main Agricultural Research Station, University of Agricultural Sciences, Raichur-584-104, Karnataka, India

${ }^{3}$ Department of Biotechnology and Crop Improvement, K.R.C. College of Horticulture, Arabhavi-591218, University of Horticultural Sciences, Bagalkot, Karnataka, India

${ }^{4}$ Indian Institute of Oilseeds Research, Rajendranagar, Hyderabad-500-030, Telangana, India

*Corresponding author

\begin{tabular}{|c|c|}
\hline \multicolumn{2}{|r|}{ A B S T R A C T } \\
\hline & \multirow{5}{*}{$\begin{array}{l}\text { Globally, Sunflower (Helianthus annuus L.) is one of the most important cultivated oilseed } \\
\text { crops. High oleic sunflower oil maintains oil stability also offers a trans-free oil solution } \\
\text { for customers. They help in diminishing the cholesterol leading to a reduction in heart } \\
\text { diseases. High oleic acid content genotypes have been developed whose oil has higher } \\
\text { oxidative stability and better dietary properties than standard genotypes. An investigation } \\
\text { was envisaged to evaluate } 64 \text { genotypes (seven CMS lines, seven restorer lines, } 49 \text { derived } \\
\text { crosses and RSFH-1 hybrid as a check) using gas chromatography (GC) and molecular } \\
\text { markers to identify high oleic acid associated genotypes. Total, five simple sequence } \\
\text { repeats (SSR) markers were chosen for screening high oleic acid content genotypes, out of } \\
\text { which only one marker N1-3F showed polymorphism between high and low oleic acid } \\
\text { genotypes. Genotypes containing high-oleic acid were found A } 1 \text {, A } 2 \text {, A } 4 \text { and A } 7 \text { line in } \\
\text { CMS, R 4, R } 5 \text {, R } 6 \text { and R } 7 \text { lines in restorer, and A } 1 \text { x R } 4 \text {, A } 1 \times \text { R } 5 \text {, A } 2 \times R 2 \text {, A } 2 \text { x R } \\
4 \text {, A } 2 \times \text { R } 7 \text {, A } 4 \text { x R } 2 \text {, A } 4 \text { x R } 6 \text { lines in derived crosses and marker N1-3F which has } \\
\text { exhibited } 749 \text { bp band length and further, results were also confirmed by determining the } \\
\text { fatty acid composition. The results of this work allowed to validation of one SSR marker } \\
\text { in sunflower genotypes for high oleic acid trait. }\end{array}$} \\
\hline $\begin{array}{l}\text { Helianthus annuus L., } \\
\text { High-oleic acid, Gas } \\
\text { Chromatography, SSR } \\
\text { marker }\end{array}$ & \\
\hline Article & \\
\hline & \\
\hline & \\
\hline
\end{tabular}

Key message

We report sunflower genotypes with high oleic acid content using gas chromatography analysis and SSR marker N1-3F differentiated high and low oleic acid content in lines derived from CMS, restores, derived crosses with hybrid (RSFH-1) as check having high oleic acid content. 


\section{Introduction}

Sunflower (Helianthus annuus L.) is an annual oil seed crop belongs to the family Asteraceae. It is a highly cross-pollinated crop. It is native to North America, extensively grown in Russia, Argentina, France, Spain, USA, China, and India. Sunflower developed as a premier oilseed crop in Russia and has found wide acceptance throughout Europe. The high oil content lines from Russia were introduced into U.S. after World War II, which rekindled interest in this crop in the USA. It is taking prime position in the oilseed economy both at a national and international level, mainly because of quality oil of the high level of poly unsaturated fatty acid. It performs well in temperate regions (Anon., 2015). In India sunflower is being grown in over an area of 0.55 million hectares (mha) with a production of 0.41 million tonnes (MT) with a productivity of $752 \mathrm{~kg} \mathrm{ha}{ }^{-1}$. Presently Karnataka is the leading state in the India, contributing 63.76 per cent and 53.70 per cent of total area and production, respectively (Anon., 2015-16). It is the second most important oilseed crop after groundnut in the Karnataka with an area of 0.35 mha and production of 0.21 MT. However, productively (597 $\mathrm{kg} \mathrm{ha}^{-1}$ ) is relatively less compared to the national average of $752 \mathrm{~kg}$ ha-1 (Anon., 2015). Since fatty acids that cannot be synthesized in the human body but most required for human health are designated as essential fatty acids (EFA) and grouped to the class poly unsaturated fatty acids (PUFA). Non-essential fatty acids grouped to class mono unsaturated fatty acids (MUFA). The PUFA is grouped into two categories, omega3 (Linolenic acid) and omega-6 (Linoleic acid) (Singh 2005), and MUFA can be grouped into one category i.e., omega-9 (Oleic acid). The saturated fatty acid (SFA) constitutes palmitic acid and stearic acid, which are unsuitable for human health. Sunflower oil is premium oil because of its light in colour, bland flavor, high smoke point and good nutritional quality. The oil content varies from 30-48 per cent. The fatty acid composition of sunflower oil is: palmitic acid (SFA): 5-8 per cent, stearic acid (SFA) 4-6 per cent, oleic acid (MUFA) omega-9 (18:1): 25-30 per cent, linoleic acid (PUFA) omega-6 (18:2): 60-72 per cent and also quality of protein 14-19 per cent (Anon., 2015-16). It holds second position in the world in edible oil manufacturing followed by soybean oil and found to be rich in minerals like magnesium, iron, copper, calcium, zinc, sodium, potassium, phosphorus, selenium and manganese and grouped among prominent plant oils for human diet due to its nutritional values (Skoric et al., 2008). It is nutritionally important because of the proportion of oleic acid and linoleic acid content, which determine the proportion of polyunsaturated fatty acid. There is a genetic variation in the fatty acid composition in sunflower oil (Cumminis et al., 1967; Simpson and George, 1985). High oleic acid (MUFA) sunflower is usually defined as the oil has more than 60 per cent of oleic acid (Lacombe and Bervillé, 2001, Pecureanu-Joita et al., 2005). Such oil has a very neutral taste and provides very high oxidative stability without hydrogenation. High oleic sunflower oil offers a trans-free oil solution for customers. The oil has many uses including culinary purpose, bakery applications, spray coating for cereals, crackers dried fruits, non-dairy cereamens frying, preparation of cosmetics, pharmaceuticals and other uses (Fick, 1989). An intake of omega 6, Omega 3 and Omega 9 (Oleic acid) has been recommended by world health organization (WHO, 2003). They help in diminishing the cholesterol leading to a reduction in heart diseases (WHO, 2003). Since, there is a significant variability for oleic acid proportion in genotypes of sunflower, which vary from 30 to 90 per cent. Breeding efforts in sunflower have focused on modifying the proportions of fatty acids in the seed oil in order to increase its suitability for 
potential applications such as deep frying. Soldatov (1976) developed the first stable high oleic acid variety 'Pervenets' through chemical mutagenesis and further selections. All other high oleic acid lines have been derived from Pervenets. High oleic varieties typically contain 80-90 per cent oleic acid and low-linoleic acid contents of between 5-9 per cent (Gupta, 2002). The proportion of oleic acid content varies with the genotype and environmental conditions. Hence, development of high oleic acid hybrids is important in sunflower through heterosis breeding program. Therefore, the increasing current market demand for quality oil in sunflower breeding to focus towards the development of improved cultivars with increased oleic acid content and also to characterize all the parents and their derived high oleic crosses at the molecular level using molecular markers goes a long way in sunflower breeding. Molecular markers are powerful tools to study genetic variation and relate them to phenotypic variation (Varshney et al., 2005). The SSRs show high reproducibility and genomic covering, codominance, neutrality and they are markers of choice (Spooner et al., 2005). They have been extensively used to study genetic variability in different organisms. In plants SSRs are being used to assess genetic variability in germplasm collections for making an appropriate choice of parents to generate breeding populations, mapping and tagging of genes, studying the population structure and taxonomic, as well as in the analysis of phylogenetic relationships (Kalia et al., 2011). The palmitic and stearic acids were low in high oleic acid lines (Giriraj and Nagaraj, 2003). The mutation was associated with Oleoyl-phosphatidylcholine desaturase (ODS) duplications that led to the silencing of the ODS gene. As a result of silencing of the ODS gene resulted in the accumulation of high oleic acid in seed (Lacombe et al., 2009). Several studies demonstrated the importance of molecular markers in the genetic analysis of sunflower. The development of molecular markers has largely contributed to the establishment of saturated molecular maps in crop plants. A number of linkage maps using various molecular markers, including RFLP, RAPD, AFLP and SSR markers have been reported in sunflower (Berry et al., 1995; Gentzbittel et al., 1995; Tang et al., 2002; Yu et al., 2003 and Rachid Al-Chaarani et al., 2004). A dense genome-wide framework of DNA markers allow the mapping of qualitative traits and the localization of factors underlying quantitative traits (Lu et al., 2007). In breeding programme for high oleic acid sunflower, oleic acid contents of seeds are usually determined using gas chromatography. Since, environmental factors effects strongly influence seed oil composition it is difficult to differentiate between several high oleic acid alleles in high oleic acid genotypes or between homozygous or heterozygous plants for the high oleic acid trait (Harwood, 1996). As a result, genotypic selection using linked molecular markers would be independent of the environment and is, therefore, a more reliable method (PérezVich et al., 2000). The aim of this study was to characterize molecular markers linked to the high oleic acid lines/ parents and crosses of sunflower. Nagarathna et al., (2010) studied six sunflower hybrids for fatty acid profile by using single SSR marker and reported that when DNA of the hybrid (RSFH-1) along with its parental lines was amplified, the female parent and hybrid RSFH-1 showed a specific band for high oleic acid content and concluded that the marker described by Berville et al., (2009) found to be useful tool to a huge number of germplasm lines to identify high oleic types. The mean content of oleic acid of the seeds from the pervenet population is high than 60 per cent. The phenotypic determination (fatty acid analysis) does not allow rapid and early determination of high oleic genotypes. The use of molecular markers has become a popular tool for the genetic and 
breeding studies which is rapid, cheaper and simple. Therefore, an attempt has been made to evaluate sunflower CMS lines, restorer lines and their derived crosses for high oleic acid content and further molecular characterization of parents and crosses to know the polymorphism between high and low oleic acid lines using molecular markers.

\section{Materials and Methods}

\section{Plant materials}

For the purpose of characterization and identification of high oleic acid genotypes at molecular level, plant materials comprised of 64 sunflower genotypes, which includes 7 CMS lines, 7 restorer lines, 49 derived crosses and 1 check hybrid RSFH-1 obtained from Dr. I Shanker Goud, Head, All India Coordinated Research Project (AICRP) on sunflower, Main Agricultural Research Station (MARS), UAS, Raichur. The lists of plant materials along with salient features are provided (Table 1).

The experiment was laid out at MARS, UAS, Raichur, parents were sown during summer (Date of sowing (DOS) is 29-1-15) and derived crosses were sown during Kharif DOS is 3-10-15). The Randomized Block Design (RBD) was followed with two replications with a plot size of $3 \mathrm{~m} \times 1.2 \mathrm{~m}$ (two rows of three meter length) and each treatment having a row length of $3 \mathrm{~m}$ length with an inter row spacing of $60 \times 30 \mathrm{~cm}$. The selected planting material consisted of seven CMS lines and seven restorer lines. One week staggered planting was done to CMS and restorer lines to synchronize flowering and pollination. Both female and male parents were covered with cloth bags before opening of the flowers to avoid cross pollination through honey bees and wind. The crossing was affected artificially by collecting pollen separately in the plastic bags and hand pollination was practiced till all the florets are fertilized.
Seven CMS lines and seven restorer lines were crossed in all possible combination to get seeds of forty-nine crosses. Good seed setting was observed and after field maturity of the crop, all the heads were harvested separately, seeds were cleaned, dried, packed separately and stored for further studies.

\section{DNA isolation and PCR analysis}

DNA was extracted from leaves during the seedling stage by CTAB method (Doyle and Doyle, 1990). Genotyping of high and low oleic sunflower genotypes were performed using five selected SSR primers (Table 2), that were chosen from the patent obtained by Baerville et al., (2009). The PCR amplification was carried out using $20 \mu \mathrm{l}$ reaction mixtures containing $1 \times$ PCR: Initial denaturation: $94^{\circ} \mathrm{C}$ for $4 \mathrm{~min}$, Final denaturation: 1cycle of $94^{\circ} \mathrm{C}$ for $50 \mathrm{~s}$, Annealing: $58^{\circ} \mathrm{C}$ for $50 \mathrm{~s}$, Primer extension: $72^{\circ} \mathrm{C}$ for $1 \mathrm{~min}$. There were 35 cycles. However, the final extension was $2 \mathrm{~min}$ at $72^{\circ} \mathrm{C}$. Buffer, $0.2 \mu \mathrm{M}$ dNTP's, 0.5 pmol of each primer (forward \& reverse) and 0.2-0.5. Amplified PCR products were observed using $2 \%$ agarose gel electrophoresis, stained with RedSafe Nucleic Acid Staining Solution and visualized by gel imaging system (Vilber Lourmat Quantum).

\section{Fatty acid analysis}

Seed samples of each entry were analysed for their fatty acid profile with the help of Gas chromatography available at Indian Institute of Oil seed Research, Hyderabad.

Oil from seed was extracted in hexane on soxhlet apparatus (Extraction unit, E-816, Buchi). Methyl esters were obtained by a twostep catalytic process according to the slightly modified method (Ghadge and Raheman 2005). The extracted oil (100-150 mg) was treated with two per cent sulphuric acid in 
methanol $(5 \mathrm{ml})$ for $2 \mathrm{hr}$ at $60{ }^{\circ} \mathrm{C}$. After the reaction, the mixture was allowed to settle for an hour and methanol-water mixture that separated at the top was removed. The second step product at the bottom was transesterified using two $\mathrm{ml}$ of 13 per cent methanolic $\mathrm{KOH}$ for 30 minutes at $55{ }^{\circ} \mathrm{C}$. The organic phase was extracted with hexane and washed with water till it reaches to neutral $\mathrm{pH}$. The hexane was dried over anhydrous sodium sulphate and concentrated with nitrogen to get methyl esters. Fatty acid composition was determined using an Agilent 7860A gas chromatograph (GC) equipped with a flame ionization detector (FID) and an auto sampler. Peak separation was performed on a DB-225 capillary column (Diameter-250 $\mu \mathrm{m}$, Length$30 \mathrm{~m}$, film thickness- $0.25 \mu \mathrm{m}$ ) from Agilent Technology. The carrier gas was nitrogen set to a constant gas flow of $1.2 \mathrm{ml} / \mathrm{min}$ at $160{ }^{\circ} \mathrm{C}$ initial temperature. Sample of $0.2 \mu \mathrm{l}$ was injected at a 20:1 split ratio into the column with the following temperature conditions: $160{ }^{\circ} \mathrm{C}$ for $2 \mathrm{~min}$; raised from 150 to $220{ }^{\circ} \mathrm{C}$ at $6{ }^{\circ} \mathrm{C} / \mathrm{min}$. Both inlet and detector were set to $230{ }^{\circ} \mathrm{C}$. Fatty acid composition was determined by identifying and calculating relative peak areas percent by GC post run analysis EZChrom elite compact software.

\section{Estimation of oil content (\%)}

Properly cleaned twelve grams seeds of each entry were oven dried at $70^{\circ} \mathrm{C}$ for three hours to determine for their oil content with the help of NMR (Nuclear magnetic resonance) spectrometer (MARS,UAS, Raichur) which provides the oil content in terms of percentage.

\section{Results and Discussion}

The present investigation was envisaged to evaluate parents and derived crosses with molecular diversity and with a view to identify best parents and hybrids for high oleic acid content. Observations were recorded on fatty acid profile, oil content. Identifying best parents and hybrids for high oleic acid content, higher seed yield and total oil content is one of the way to develop a high oleic acid hybrids in oil seed crops. Keeping this in view, seven CMS lines, seven restorer lines, 49 derived crosses and one check hybrid (RSFH-1) were evaluated for molecular characterization. Results obtained from the present investigation are furnished under following headings.

\section{Fatty acid analysis}

The sunflower fatty acid profile includes estimation of various proportion of palmitic acid (C16:0), stearic acid (C18:0), oleic acid (C18:1) and linoleic acid (C18:2) expressed interms of percentages. Fatty acid profile of seven CMS lines, seven restorer lines and 49 derived crosses along with check hybrid RSFH-1 was estimated by using gas chromatography. The results obtained for four fatty acids viz., palmitic acid, stearic acid, oleic acid and linoleic acid along with total oil content are presented in Table 3. The proportion of palmitic acid was low in CMS lines A 1 (5.33\%), A 2 (5.34\%), A 4 (5.30\%) and A 7 (5.04\%), in restorer lines the lowest recorded was R 4 (4.25\%), R 6 (4.9\%) and R 7 $(4.83 \%)$, while in 49 derived crosses, it ranged from 3.86 to 7.73 per cent. Among the top high oleic acid crosses it recorded very high proportion of palmitic acid which ranged from 3.86 to 7.02 per cent compare to the check hybrid (RSFH 1) linoleic acid genotypes $(5.08 \%)$ (Table 4). Stearic acid is categorized as saturated fatty acid, the higher concentrations is an undesirable oil quality characteristic. In case of CMS lines, the low proportion was recorded in A 4 (3.73\%), A 6 $(4.95 \%)$ and A 7 (3.38\%), in restorer lines it was lowest in R 1 (2.93\%), R 7 (3.48\%), R 6 $(3.92 \%)$ and $\mathrm{R} 2(3.96 \%)$. While in 49 derived crosses it recorded very low proportion from 
2.92 to 5.45 per cent. Among top seven crosses it recorded high proportion which ranged from 2.92 to 4.15 per cent compare to the check hybrid (RSFH1) (3.04\%) (Table 4). In case of oleic acid, three CMS lines viz., A 2 (74.03\%), A 4 (79.30\%) and A 7 (60.33\%), four restorer lines viz., R 4 (85.21\%), R 5 (66.24\%), R 6 (68.92\%) and R $7(77.61 \%)$ exhibited high oleic acid content. Among derived crosses, three crosses were found to be significantly higher oleic acid content viz., A $1 \times$ R 4 (82.02\%), A 2 x R 2 (81.29\%) and A 4 $x$ R $2(78.64 \%)$ compared to check hybrid RSFH-1 (78.64\%) (Table 4.). In linoleic acid estimation, two CMS lines showed 11.66 and 14.38 per cent in A 4 and A 2 respectively. In restorer lines R 4 has very low linoleic acid (6.32\%) followed by R 7 (14.04\%). Among derived crosses, three crosses exhibited very low proportion viz., A 1 x R 1 (9.32\%), A 2 x R 2 (11.10\%) and A 4 x R 2 (11.30\%) (Table $3)$. The chromatogram of fatty acid profile of high oleic crosses are given in Figure 1 and 2, low oleic acid in Figure 3 and 4 along with high oleic check hybrid in Figure 5.

\section{Estimation of oil content (\%)}

The oil content in CMS lines ranged from 33.64 (A 2) to 40.75 (A 3) per cent, in restorer lines it varied from 34.15 (R 1) to 39.80 (R 7) per cent and in crosses it ranged from 27 (A 2 x R 2) to 40.90 (A 7 x R 6) per cent. Out of seven CMS lines \& seven restorer lines, one A $3(40.75 \%)$ and one R 7 (39.80\%) showed high oil content. Among 49 crosses, A 7 x R 6 $(40.90 \%)$ revealed high oil content, compare to check hybrid RSFH-1 (37.75\%).

\section{Molecular characterization of the parents and derived crosses using SSR markers}

A total of five SSR markers were used to screen seven CMS lines, seven restorer lines, 49 derived crosses and check hybrid RSFH-1. Experiment results revealed that, out of five markers used only one marker, N1-3F/N1-3R, produced polymorphic amplicon differentiating high oleic and low oleic acid types in sunflower (Fig. 6 and 7). The high oleic associated amplicon was specific at 749 bp for the parental lines CMS A 1, A 2, A 4 and A 7 and restorer lines R 4, R 5, R 6, R 7 and for seven derived crosses (A 1 x R 4, A 1 x R 5, A 2 x R 2, A 2 x R 4, A 2 x R 7, A 4 x R 2, A 4 x R 6) (Fig. 8). For mid oleic lines A $3, \mathrm{R} 1, \mathrm{R} 3$ and 31 derived crosses and also low oleic acid lines A 5, A 6, R 2 and 11 derived crosses, the marker N1-3F depicted polymorphic amplicon at 500bp but not at 749bp (Fig. 9 and 10). While the other marker ORS-311 showed monomorphic bands for high oleic, mid oleic and low oleic acid for all seven CMS and seven restorer lines (Fig. 11). Parents and crosses showing high, mid and low oleic acid proportions in sunflower (Table 5). The amplicons obtained for seven top ranking high oleic acid crosses are presented (Table 6), this indicates the presence of high oleic acid. The high oleic specific band at 749 bp was absent in 31 mid oleic and 11 low oleic acid crosses. By identifying best parents and hybrids for high oleic acid content and total oil content, ultimately experiment lead a way to develop new high oleic acid hybrids.

Sunflower (Helianthus annuus L.) has become an important oil seed crop in the world and it is a potential source of healthy oil and protein. High oleic acid (MUFA) sunflower is usually defined as having a minimum of 60 per cent oleic acid and maximum of $80-90$ per cent. Development of high oleic acid hybrids need to be given prime importance in sunflower heterosis breeding programme. However, new technologies have introduced an additional means for improving sunflower yield and quality using molecular genetics. Molecular markers have been looked upon as tools for a large number of applications ranging from localisation of a gene to improvement of plant varieties by marker-assisted selections. 
Fig.1 The chromatogram depicting the fatty acid methyl esters with their respective peak areas and retention time for high oleic cross (A $1 \times \mathrm{R} 4, \mathrm{C} 18: 1=82.02 \%)$

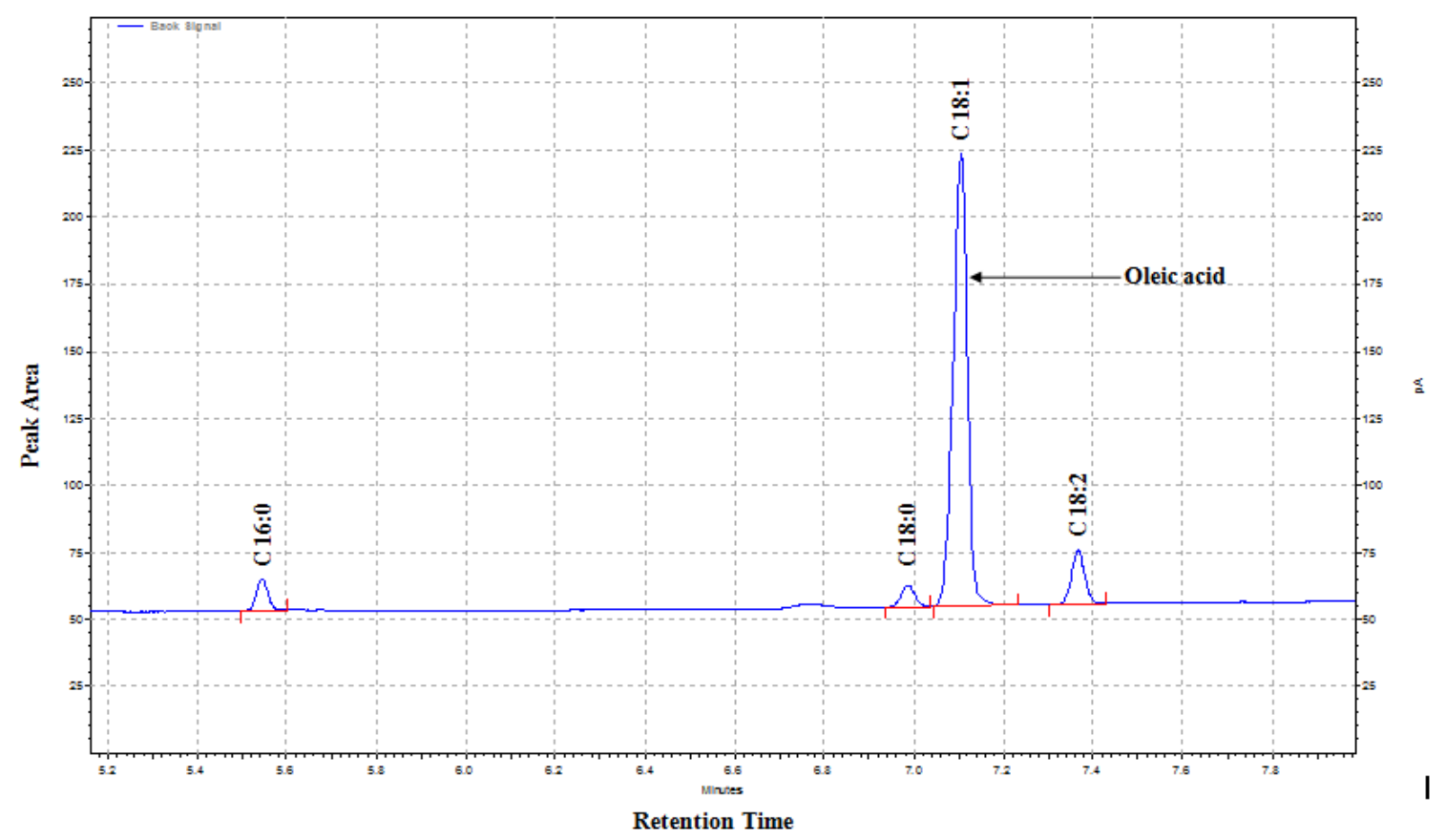

Fig.2 The chromatogram depicting the fatty acid methyl esters with their respective peak areas and retention time for high oleic cross (A $2 \times \mathrm{R} 2, \mathrm{C} 18: 1=81.29 \%$ )

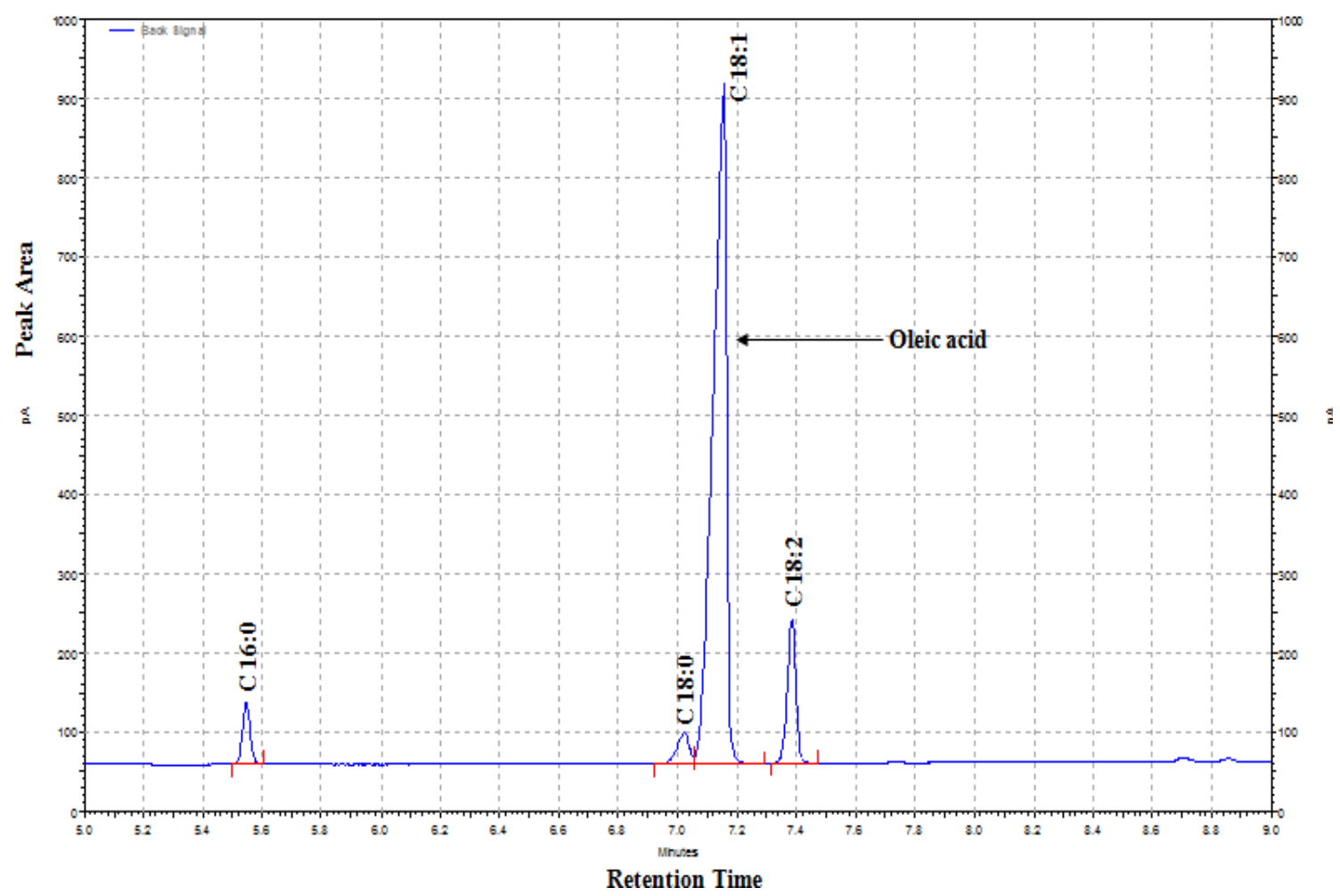


Fig.3 The chromatogram depicting the fatty acid methyl esters with their respective peak areas and retention time for low oleic cross (A 6 x R 1, C18:1 = 20.43\%).

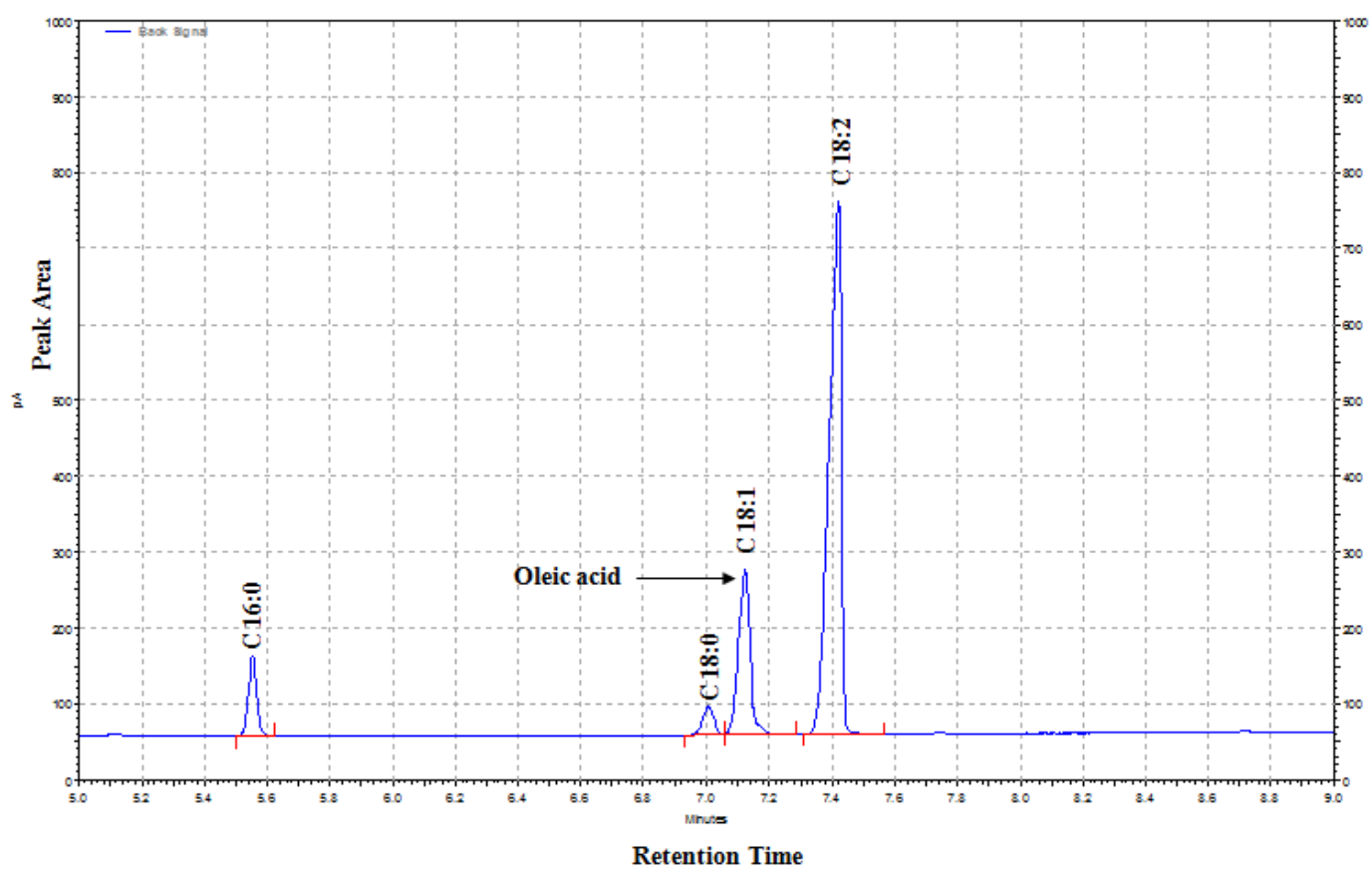

Fig.4 The chromatogram depicting the fatty acid methyl esters with their respective peak areas and retention time for low oleic cross (A 4 x R 1, C18:1 = 24.41\%)

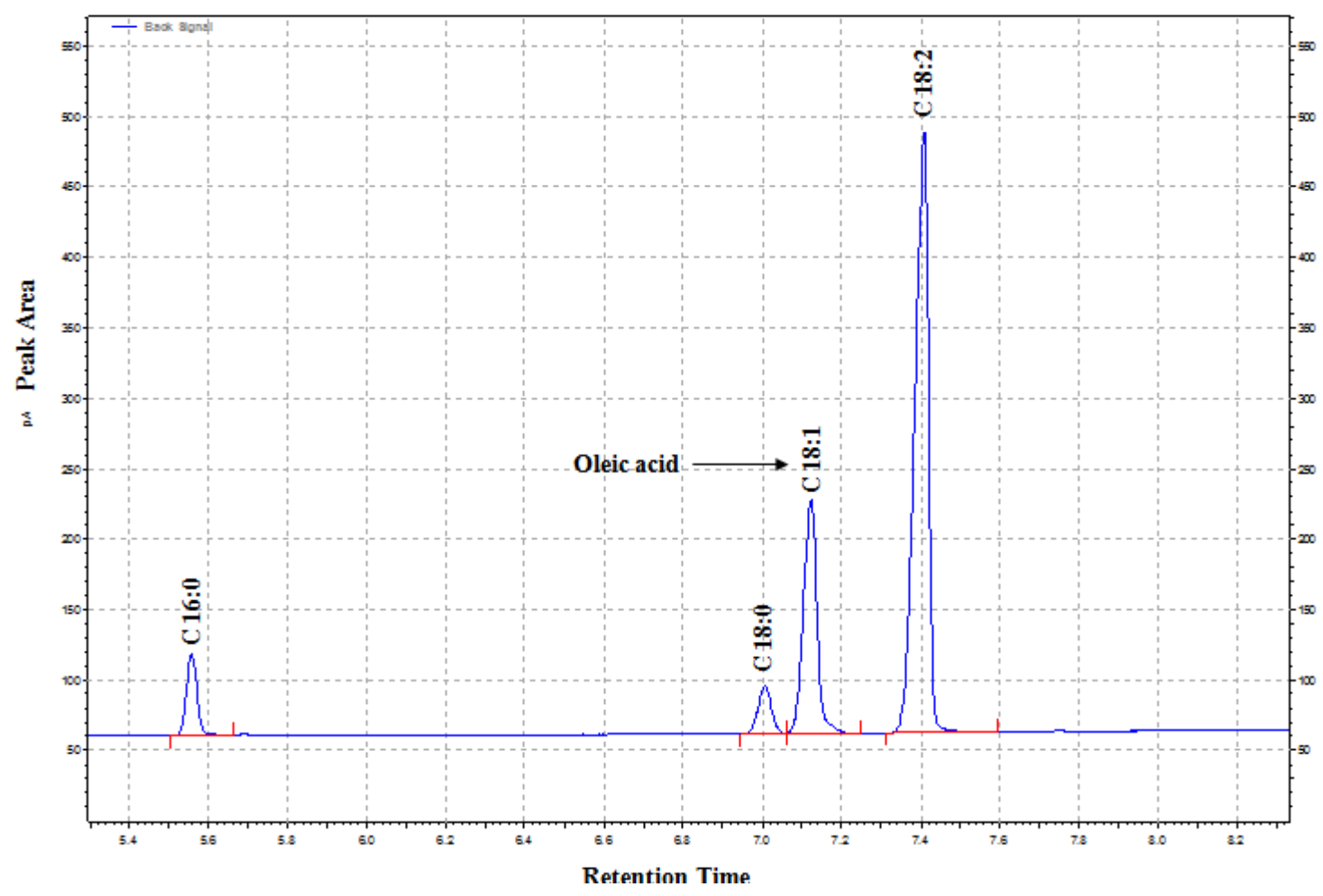


Fig.5 The chromatogram depicting the fatty acid methyl esters with their respective peak areas and retention time for high oleic check hybrid (RSFH-1, C18:1 =78.64\%)

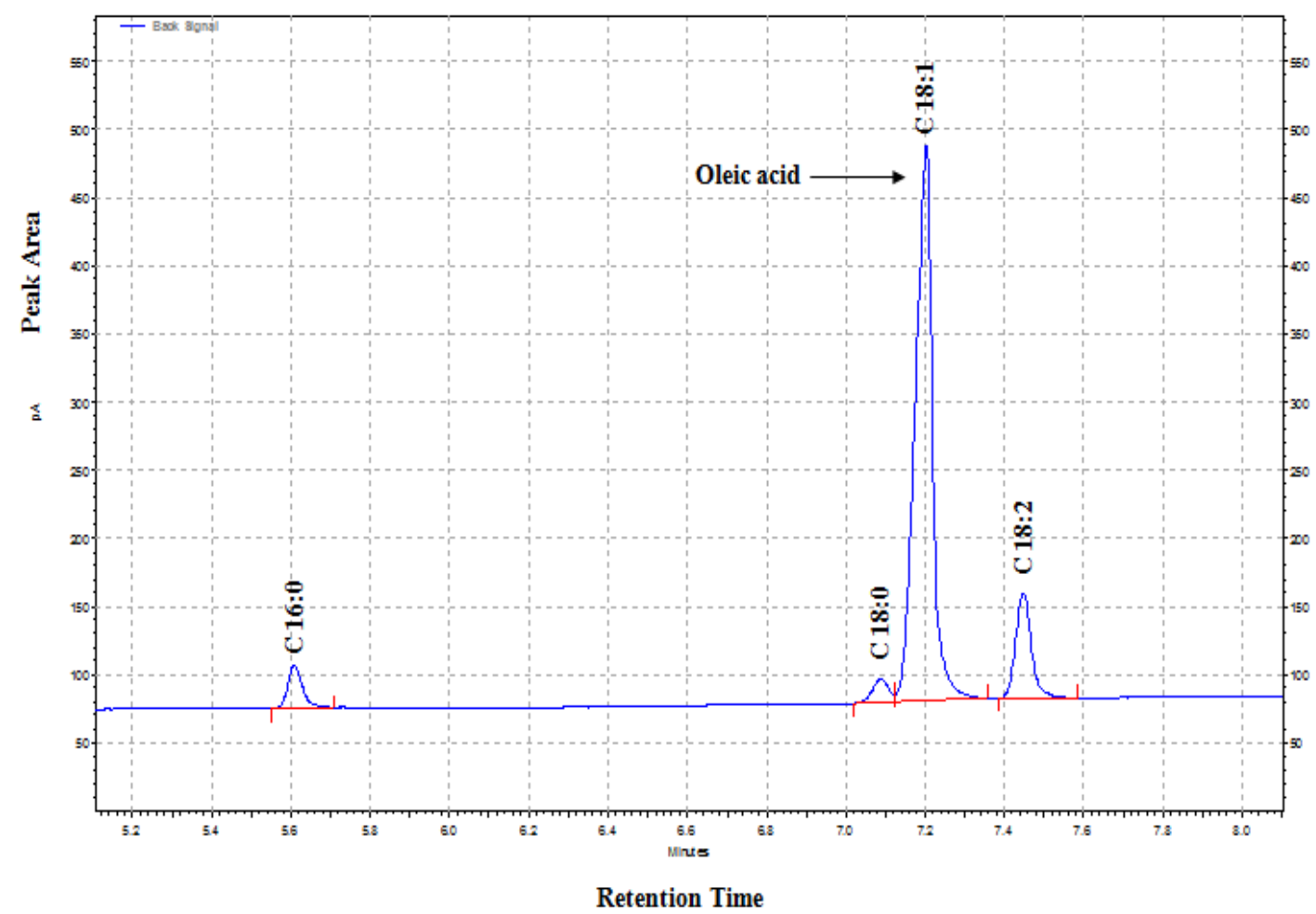

Fig.6 PCR amplicon patterns for high oleic (HO), mid oleic (MO) and low oleic (LO) parental lines, generated by marker N1-3F

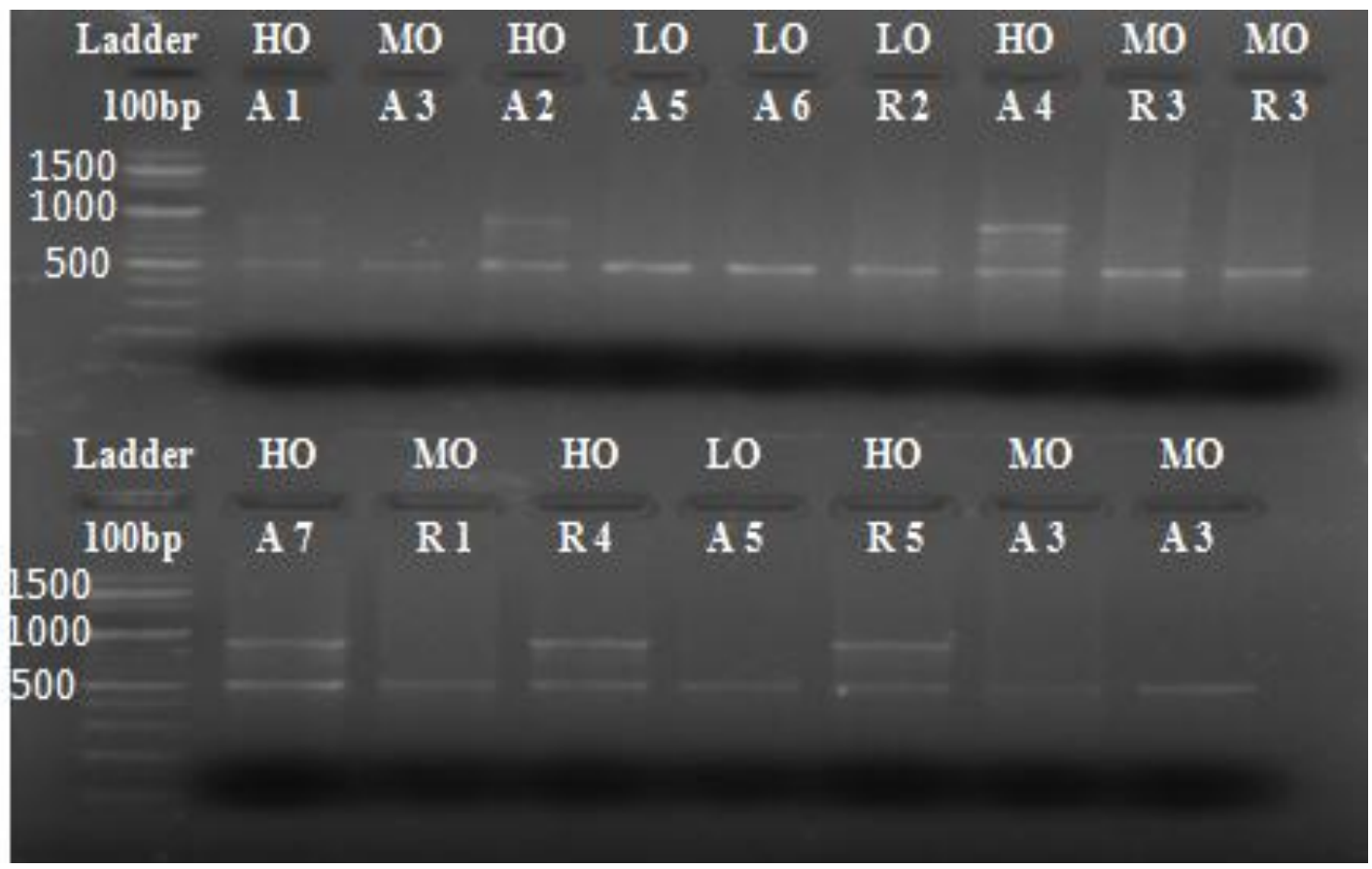


Fig.7 PCR amplicon patterns for high oleic (HO) parental lines, generated by marker N1-3F

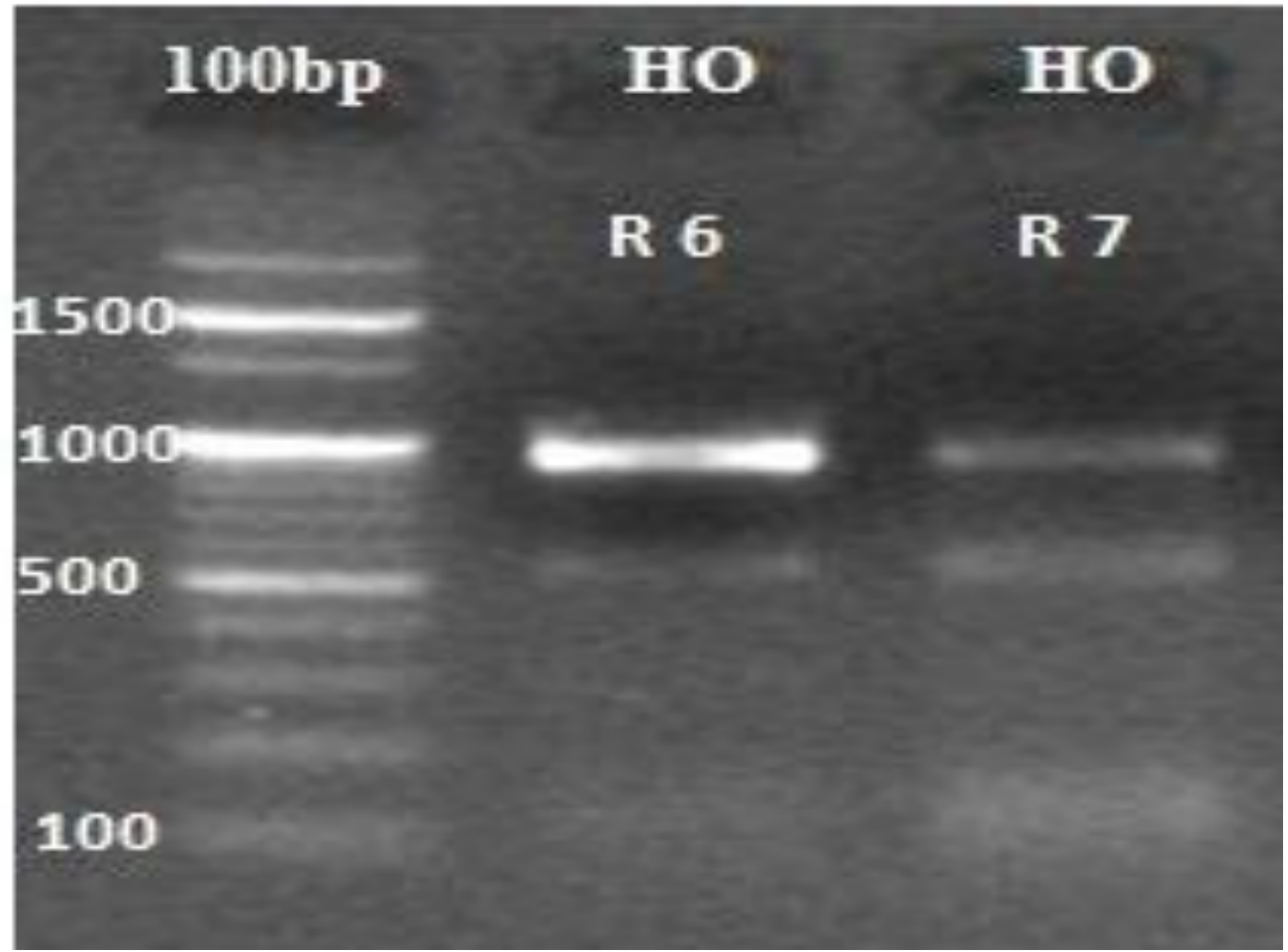

Fig.8 PCR amplicon patterns for high oleic (HO) derived crosses along with check, generated by marker $\mathrm{N} 1-3 \mathrm{~F}$

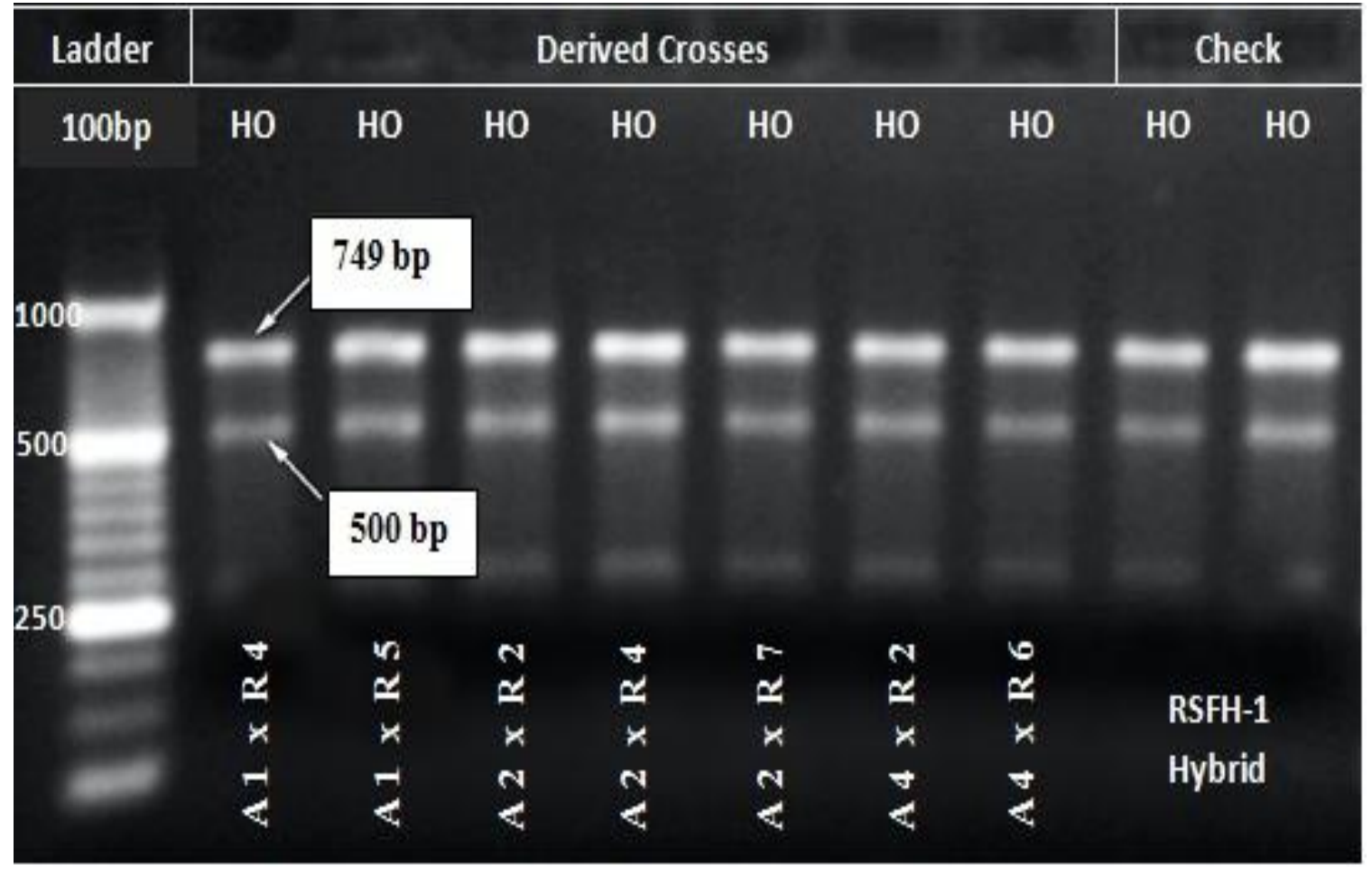


Fig.9 PCR amplicon patterns for mid oleic (MO) derived crosses, generated by marker N1-3F

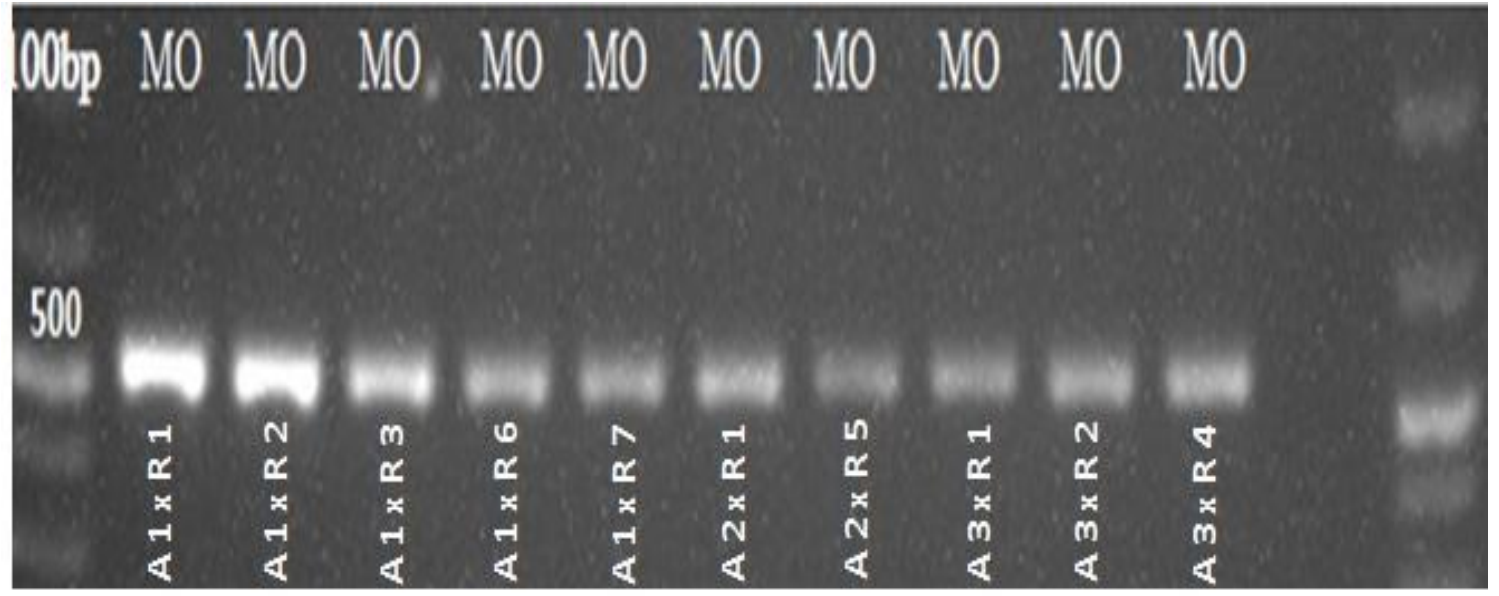

Fig.10 PCR amplicon patterns for low oleic (LO) derived crosses, generated by marker N1-3F

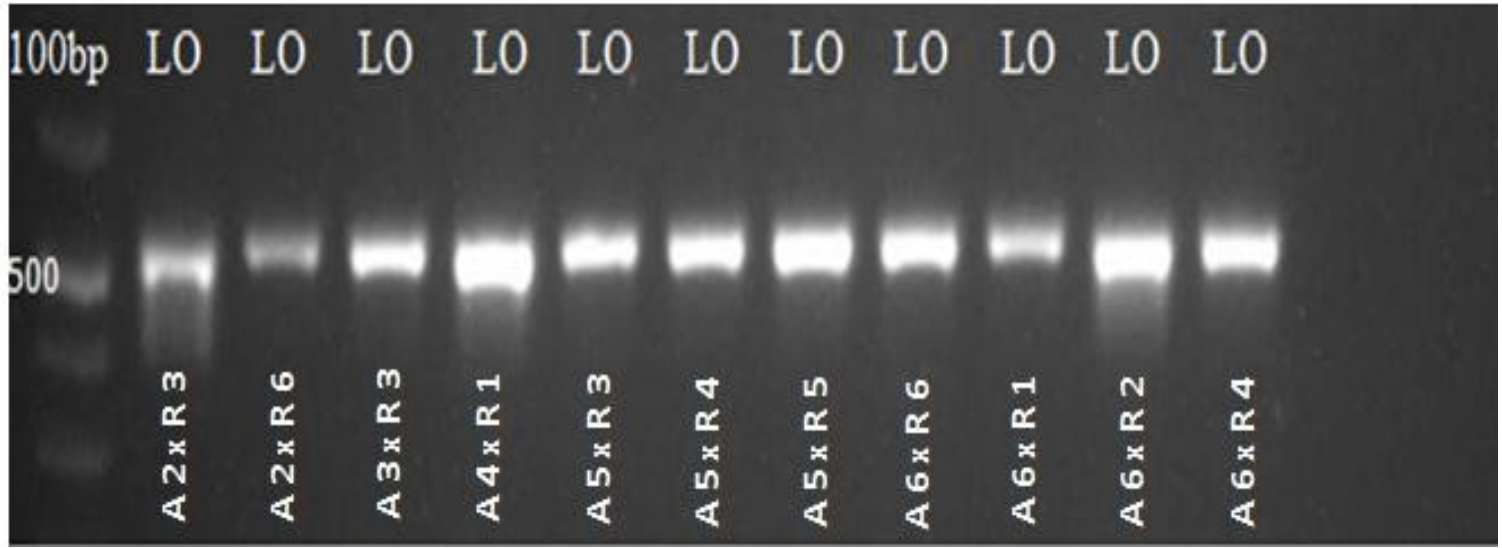

Fig.11 PCR amplicon patterns for high oleic (HO), mid oleic (MO) and low oleic (LO) parental lines, generated by marker ORS-311

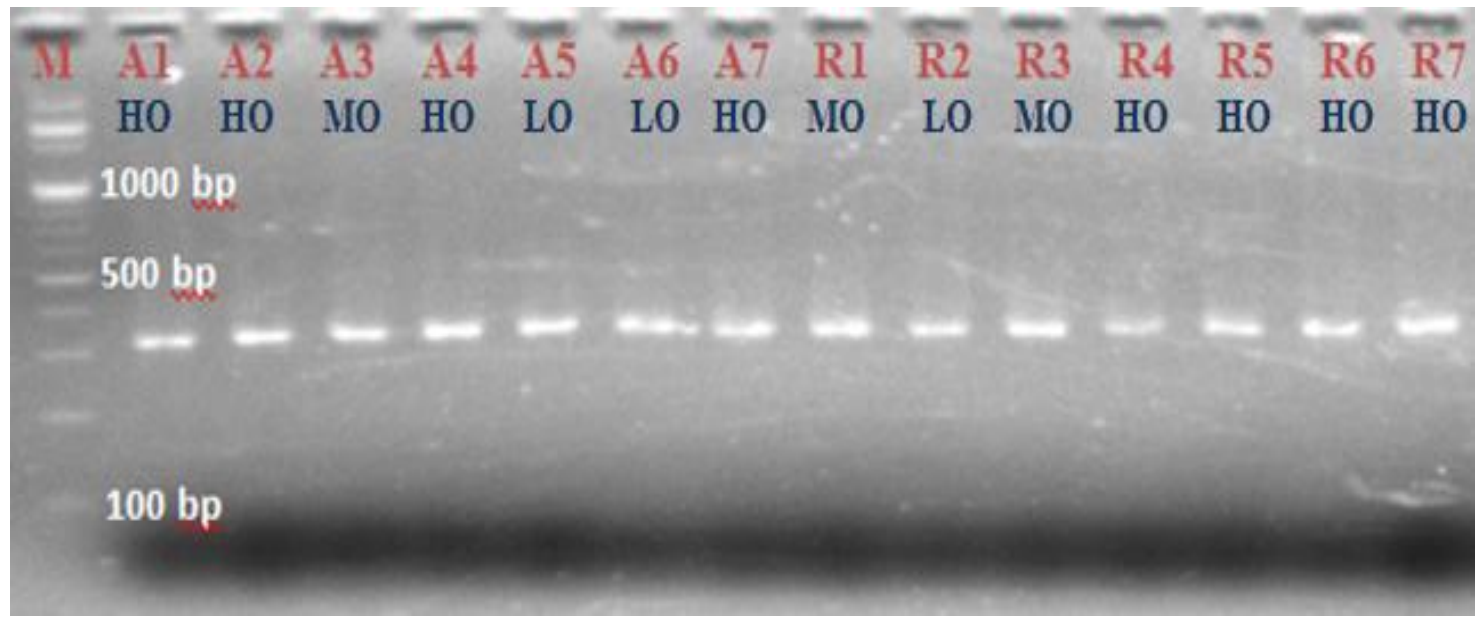


Table.1 Salient features of sunflower CMS and restorer lines used in the study

\begin{tabular}{|c|c|c|c|c|c|c|c|c|c|c|}
\hline \multirow{2}{*}{$\begin{array}{l}\text { Sl. } \\
\text { No. }\end{array}$} & \multirow{2}{*}{$\begin{array}{c}\text { Parents/ } \\
\text { Inbred lines }\end{array}$} & \multirow{2}{*}{$\begin{array}{c}\text { Abbreviations } \\
\text { used }\end{array}$} & \multirow{2}{*}{$\begin{array}{l}\text { Plant } \\
\text { height } \\
(\mathrm{cm})\end{array}$} & \multirow[t]{2}{*}{ DFF } & \multirow{2}{*}{$\begin{array}{c}\text { Oil } \\
\text { content } \\
(\%)\end{array}$} & \multicolumn{4}{|c|}{ Fatty acid profile (\%) } & \multirow[t]{2}{*}{ Plant type } \\
\hline & & & & & & $\begin{array}{l}\text { Oleic } \\
\text { acid }\end{array}$ & $\begin{array}{c}\text { Linoleic } \\
\text { acid }\end{array}$ & $\begin{array}{c}\text { Palmitic } \\
\text { acid }\end{array}$ & $\begin{array}{c}\text { Stearic } \\
\text { acid }\end{array}$ & \\
\hline \multicolumn{11}{|c|}{ CMS lines } \\
\hline 1 & CMS-3109A & A 1 & 155 & 56 & 33.78 & 63.00 & 25.1 & 5.33 & 6.56 & Non branched \\
\hline 2 & CMS-3114A & A 2 & 145 & 60 & 33.29 & 74.02 & 14.38 & 5.34 & 6.26 & Non branched \\
\hline 3 & CMS-3137A & A 3 & 130 & 57 & 40.50 & 35.28 & 51.59 & 7.97 & 5.16 & Non branched \\
\hline 4 & CMS-103A & A 4 & 160 & 58 & 37.60 & 79.30 & 11.66 & 5.3 & 3.73 & Non branched \\
\hline 5 & CMS-400A & A 5 & 115 & 60 & 36.70 & 20.79 & 65.28 & 7.32 & 6.62 & Non branched \\
\hline 6 & CMS-852A & A 6 & 140 & 58 & 34.50 & 25.13 & 61.16 & 8.76 & 4.95 & Non branched \\
\hline 7 & CMS-1511A & A 7 & 135 & 65 & 36.20 & 60.33 & 31.25 & 5.04 & 3.38 & Non branched \\
\hline \multicolumn{11}{|c|}{ Restorer lines } \\
\hline 1 & RHA-349 & R 1 & 160 & 55 & 33.86 & 47.63 & 41.42 & 8.02 & 2.93 & Branched \\
\hline 2 & RHA-64NB & R 2 & 130 & 65 & 35.76 & 26.47 & 62.50 & 7.27 & 3.96 & Non branched \\
\hline 3 & RHA-1072 & R 3 & 135 & 56 & 37.27 & 41.79 & 46.92 & 6.59 & 4.7 & Branched \\
\hline 4 & RHA-1390 & R 4 & 155 & 59 & 35.65 & 85.21 & 6.32 & 4.25 & 4.22 & Non branched \\
\hline 5 & RHA-1393 & R 5 & 125 & 64 & 34.20 & 66.24 & 21.97 & 5.8 & 5.98 & Branched \\
\hline 6 & RHA-3000 & R 6 & 140 & 56 & 35.00 & 68.92 & 22.36 & 4.9 & 3.92 & Branched \\
\hline 7 & RHA-3003 & R 7 & 170 & 62 & 39.10 & 77.61 & 14.08 & 4.83 & 3.48 & Branched \\
\hline
\end{tabular}


Table.2 List of sunflower SSR markers used in the study

\begin{tabular}{|c|c|c|}
\hline SI. No. & Primers name & Sequence $\left(5^{\prime}-3^{\prime}\right)$ \\
\hline \multirow[t]{2}{*}{1} & $\mathrm{~N} 1-3 \mathrm{~F} \mathrm{~F}$ & GAGAAGAGGGAGGTGTGAAG \\
\hline & N1-3F R & AGCGGTTATGGTGAGGTCAG \\
\hline \multirow[t]{2}{*}{2} & ORS $-311 \mathrm{~F}$ & TCCCGAATTAGCCAAAGAAC \\
\hline & ORS -311 R & GGTGTGGGTGTTGCAGCTAT \\
\hline \multirow[t]{2}{*}{3} & ORS- $339 \mathrm{~F}$ & СССТСТТССТСТСССТТАСТТТ \\
\hline & ORS- $339 \mathrm{R}$ & AAATCCGCACTCCAATATGC \\
\hline \multirow[t]{2}{*}{4} & ORS- $371 \mathrm{~F}$ & GGTGCCTTCTCTTCCTTGTG \\
\hline & ORS- $371 \mathrm{R}$ & CACACCACCAAACATCAACC \\
\hline \multirow[t]{2}{*}{5} & ORS- $488 \mathrm{~F}$ & CCCATTCACTCCTGTTTCCA \\
\hline & ORS- $488 \mathrm{R}$ & CTCCGGTGAGGATTTGGATT \\
\hline
\end{tabular}

Table.3 Estimates of four fatty acids along with oil content in CMS, restorer lines and derived crosses in sunflower

\begin{tabular}{|c|c|c|c|c|c|}
\hline \multirow{2}{*}{$\begin{array}{c}\text { Parents/ } \\
\text { Crosses }\end{array}$} & \multirow{2}{*}{$\begin{array}{c}\text { Oil content } \\
(\%)\end{array}$} & \multicolumn{4}{|c|}{ Fatty acids (\%) } \\
\hline & & Palmitic acid & Stearic acid & Oleic acid & Lenoleic acid \\
\hline \multicolumn{6}{|l|}{ CMS lines } \\
\hline A 1 & 33.89 & 5.33 & 6.56 & $63.00++$ & 25.1 \\
\hline A 2 & 33.64 & 5.34 & 6.26 & $74.02++$ & 14.38-- \\
\hline A 3 & 40.75 & 7.97 & 5.16 & 35.28 & 51.59 \\
\hline A 4 & 37.80 & 5.30 & $3.73-$ & $79.30++$ & 11. 66-- \\
\hline A 5 & 37.10 & 7.32 & 6.62 & 20.79 & 65.28 \\
\hline A 6 & 34.75 & 8.76 & 4.95 & 25.13 & 61.16 \\
\hline A 7 & 36.60 & 5.04 & $3.38-$ & $60.33++$ & 31.25 \\
\hline Mean & 36.36 & 6.44 & 5.24 & 51.12 & 35.54 \\
\hline Range & $33.64-40.75$ & $5.3-8.76$ & $3.38-6.62$ & $20.79-79.02$ & $11.66-65.28$ \\
\hline \multicolumn{6}{|c|}{ Restorer lines } \\
\hline R 1 & 34.15 & 8.02 & 2.93- & 47.63 & 41.42 \\
\hline R 2 & 35.35 & 7.27 & $3.96-$ & 26.47 & 62.5 \\
\hline R 3 & 37.88 & 6.59 & 4.70 & 41.79 & 46.92 \\
\hline $\mathbf{R 4}$ & 36.07 & $4.25-$ & 4.22 & $85.21++$ & 6.32-- \\
\hline R 5 & 35.00 & 5.80 & 5.98 & $66.24++$ & 21.97 \\
\hline R 6 & 35.75 & $4.90-$ & $3.92-$ & $68.92++$ & 22.36 \\
\hline $\mathbf{R} 7$ & 39.80 & $4.83-$ & $3.48-$ & $77.61++$ & 14.08-- \\
\hline Mean & 36.29 & 5.95 & 4.17 & 59.12 & 30.80 \\
\hline Range & $35.00-39.80$ & $4.25-7.27$ & 3.48- 5.98 & $26.47-85.21$ & $6.32-62.50$ \\
\hline A $1 \times R 1$ & 30.65 & 6.36 & $3.52-$ & 43.01 & 47.11 \\
\hline A $1 \times R 2$ & 29.90 & 5.63 & $3.67-$ & 38.48 & 52.22 \\
\hline A $1 \times R 3$ & 36.50 & 5.47 & $3.20-$ & 50.76 & 40.57 \\
\hline A $1 \times R 4$ & 38.75 & 4.79- & $3.87-$ & $82.02++$ & 9.32-- \\
\hline A $1 \times R 5$ & 35.00 & 3.86- & $3.53-$ & $66.19++$ & 26.42 \\
\hline A $1 \times R 6$ & 37.80 & 5.64 & 4.21 & 31.79 & 58.36 \\
\hline A $1 \times R 7$ & 36.50 & 6.66 & 5.45 & 31.87 & 56.02 \\
\hline A $2 \times$ R 1 & 35.60 & 6.31 & $3.75-$ & 30.67 & 59.27 \\
\hline
\end{tabular}




\begin{tabular}{|c|c|c|c|c|c|}
\hline A $2 \times R 2$ & 27.00 & $4.31-$ & $3.31-$ & $81.29++$ & 11.10-- \\
\hline A 2x R 3 & $38.50+$ & 6.17 & 4.64 & 29.47 & 59.72 \\
\hline A $2 \times R 4$ & 30.05 & 5.45 & $2.92-$ & $65.3++$ & 26.33 \\
\hline A $2 \times R 5$ & 36.70 & 5.17 & $3.44-$ & 52.9 & 38.49 \\
\hline A $2 \times R 6$ & $38.85+$ & 6.46 & $3.62-$ & 29.22 & 60.70 \\
\hline A $2 \times R 7$ & 36.90 & 5.23 & $3.83-$ & $60.93++$ & 30.02 \\
\hline A 3x R 1 & 37.00 & 5.02 & $3.72-$ & 55.05 & 36.21 \\
\hline A $3 \times R 2$ & $38.85+$ & 6.02 & 4.26 & 33.16 & 56.56 \\
\hline A 3x R 3 & $39.75+$ & 5.95 & 5.35 & 26.86 & 61.85 \\
\hline \multirow[t]{2}{*}{ Crosses } & \multirow{2}{*}{$\begin{array}{l}\text { Oil content } \\
(\%)\end{array}$} & \multicolumn{4}{|c|}{ Fatty acids (\%) } \\
\hline & & Palmitic acid & Stearic acid & Oleic acid & Lenoleic acid \\
\hline A $3 \times R 4$ & 35.25 & 7.44 & 4.22 & 30.41 & 57.93 \\
\hline A $3 \times R 5$ & $38.90+$ & 7.60 & 4.28 & 30.26 & 57.86 \\
\hline A $3 \times R 6$ & 35.75 & 5.85 & $3.38-$ & 51.78 & 38.99 \\
\hline A $3 \times R 7$ & $38.00+$ & 6.86 & 4.89 & 30.16 & 58.09 \\
\hline A 4xR1 & 32.10 & 6.65 & 4.83 & 24.41 & 64.12 \\
\hline A 4xR2 & 37.75 & 7.02 & 4.15 & $77.50++$ & 11.30-- \\
\hline A 4xR3 & 34.50 & 6.09 & 4.80 & 32.00 & 57.10 \\
\hline A $4 \times R 4$ & 33.05 & 6.21 & $3.67-$ & 38.60 & 51.51 \\
\hline A 4xR 5 & 34.75 & 5.81 & $3.56-$ & 41.16 & 49.48 \\
\hline A 4xR 6 & 33.75 & 4.94- & 3.79- & $60.37++$ & 30.90 \\
\hline A 4xR7 & 36.75 & 6.14 & $3.53-$ & 35.56 & 54.77 \\
\hline A $5 \times R 1$ & $38.85+$ & 6.24 & 4.67 & 30.32 & 58.77 \\
\hline A $5 \times R 2$ & 34.20 & 6.98 & $3.98-$ & 31.43 & 57.61 \\
\hline A $5 \times R 3$ & 37.15 & 7.73 & 4.23 & 27.81 & 60.23 \\
\hline A $5 \times R 4$ & 37.20 & 7.71 & $3.21-$ & 25.58 & 63.5 \\
\hline A $5 \times R 5$ & 37.85 & 7.05 & $3.26-$ & 27.83 & 61.86 \\
\hline A $5 \times R 6$ & 37.10 & 7.38 & 3.79- & 23.13 & 65.71 \\
\hline A $5 \times R 7$ & 33.20 & 6.14 & 4.50 & 32.30 & 57.07 \\
\hline A $6 \times R 1$ & $40.25+$ & 6.95 & $3.37-$ & 20.43 & 69.26 \\
\hline A 6xR 2 & 37.25 & 7.56 & 3.09- & 23.74 & 65.61 \\
\hline A 6xR3 & 34.60 & 5.81 & 4.75 & 31.88 & 57.56 \\
\hline A $6 \times R 4$ & $38.20+$ & 7.20 & $3.97-$ & 26.13 & 62.70 \\
\hline A $6 \times R 5$ & 34.15 & 6.13 & $3.62-$ & 36.07 & 54.18 \\
\hline A $6 \times R 6$ & 35.55 & 5.87 & 4.21 & 39.98 & 49.94 \\
\hline A $6 \times R 7$ & 37.10 & 5.70 & 4.60 & 40.86 & 48.85 \\
\hline A 7xR 1 & 39.20 & $5.93+$ & $3.87-$ & 37.02 & 53.17 \\
\hline A 7xR 2 & 35.40 & 4.79- & $3.91-$ & 46.76 & 44.54 \\
\hline A 7xR 3 & 35.50 & 6.23 & 4.02 & 33.07 & 56.67 \\
\hline A 7xR 4 & 34.95 & 5.92 & $3.66-$ & 41.60 & 48.82 \\
\hline A 7xR 5 & 36.25 & 5.20 & $3.44-$ & 49.14 & 42.22 \\
\hline A $7 \times R 6$ & $40.90+$ & 5.51 & 5.10 & 44.19 & 45.20 \\
\hline A $7 \times R 7$ & 34.20 & 4.79- & 4.81 & 50.11 & 40.29 \\
\hline Mean & 36.00 & 6.08 & 3.99- & 40.42 & 49.51 \\
\hline Range & $27-40.9$ & $3.86-7.73$ & $2.92-5.45$ & $20.43-82.02$ & $9.32-69.26$ \\
\hline $\begin{array}{l}\text { RSFH-1 } \\
\text { (Check) }\end{array}$ & 37.75 & 5.08 & 3.04 & 78.64 & 13.24 \\
\hline
\end{tabular}

$+=$ High oil $(>38 \%), \quad++=$ High oleic acid $(>60 \%)$ and

- = low palmitic acid $(<5 \%),-=$ stearic acid $(<4 \%),--=$ low linoleic acid $(<15 \%)$. 
Table.4 Seven top ranking derived high oleic acid crosses along with check hybrid RSFH-1, showing fatty acids proportions

\begin{tabular}{|c|c|c|c|c|c|}
\hline SI. No & Derived Crosses & Oleic Acid $(\%)$ & $\begin{array}{c}\text { Linoleic Acid } \\
(\%)\end{array}$ & $\begin{array}{c}\text { Palmitic Acid } \\
(\%)\end{array}$ & $\begin{array}{c}\text { Stearic Acid } \\
(\%)\end{array}$ \\
\hline $\mathbf{1}$ & A 1 x R 4 & 82.02 & 9.32 & 4.79 & 3.87 \\
\hline $\mathbf{2}$ & A 2 x R 2 & 81.29 & 11.10 & 4.31 & 3.31 \\
\hline $\mathbf{3}$ & A 4 x R 2 & 77.50 & 11.30 & 7.02 & 4.15 \\
\hline $\mathbf{5}$ & A 1 x R & 66.19 & 26.42 & 3.86 & 3.53 \\
\hline $\mathbf{6}$ & A 2 x R 4 & 65.30 & 26.33 & 5.45 & 2.92 \\
\hline 7 & A 2 x R 7 & 60.93 & 30.02 & 5.23 & 3.83 \\
\hline Check & ASFH x R & 60.37 & 30.90 & 4.94 & 3.79 \\
\hline
\end{tabular}

Table.5 Parents and crosses showing high, mid and low oleic acid proportions in sunflower

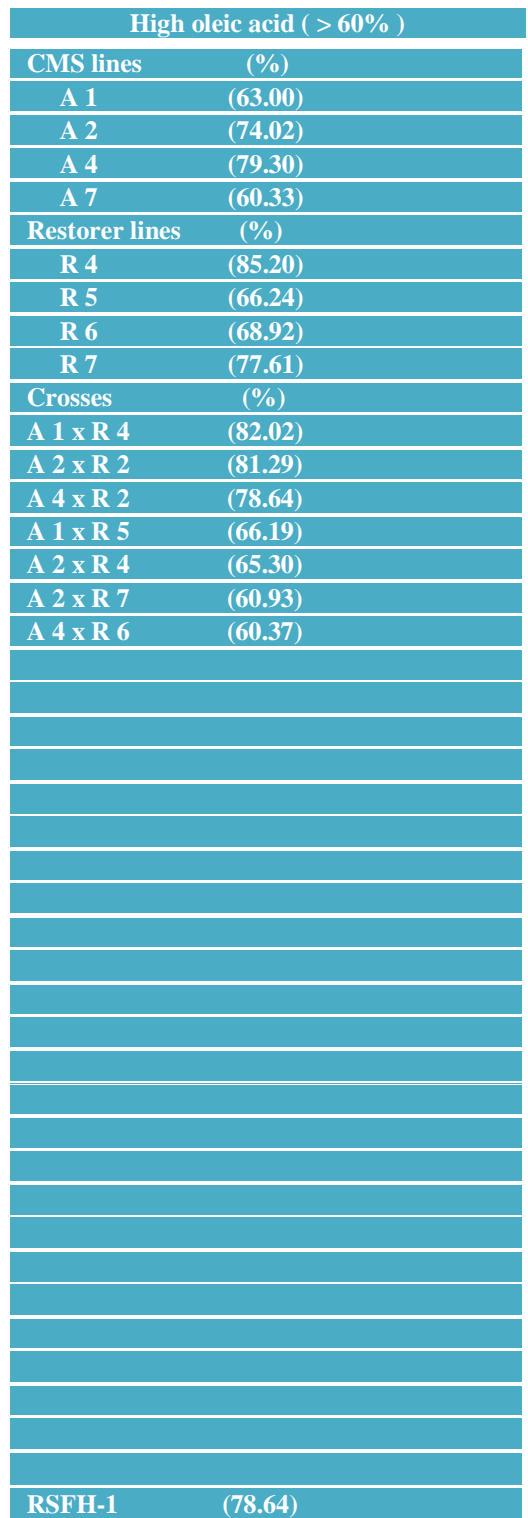

\begin{tabular}{|c|c|c|c|}
\hline \multicolumn{2}{|c|}{ Mid oleic acid ( $30-59 \%$ ) } & \multicolumn{2}{|c|}{ Low oleic acid ( $10-29 \%$ ) } \\
\hline CMS lines & $(\%)$ & CMS lines & $(\%)$ \\
\hline A 3 & (35.28) & A 5 & (20.29) \\
\hline & & A 6 & (25.13) \\
\hline Restorer lines & $(\%)$ & Restorer lines & $(\%)$ \\
\hline R 1 & (47.63) & R 2 & (26.47) \\
\hline R 3 & (41.79) & & \\
\hline Crosses & $(\%)$ & Crosses & $(\%)$ \\
\hline A $1 \times R 1$ & (43.01) & A $2 \times R 3$ & (29.47) \\
\hline A $1 \times R 2$ & (38.48) & A $2 \times R 6$ & (29.22) \\
\hline A $1 \times R 3$ & (50.76) & A $3 \times R 3$ & (26.86) \\
\hline A $1 \times$ R 6 & (31.79) & A $4 \times$ R 1 & (24.41) \\
\hline A $1 \times R 7$ & (31.87) & A $5 \times R 3$ & (27.81) \\
\hline A $2 \times R 1$ & (30.67) & A $5 \times \mathrm{R} 4$ & (25.58) \\
\hline A $2 \times R 5$ & $(52.90)$ & A $5 \times$ R 5 & (27.83) \\
\hline A $3 \times R 1$ & (55.05) & A $6 \times$ R 6 & (23.13) \\
\hline A $3 \times R 2$ & (33.16) & A $6 \times$ R 1 & (20.43) \\
\hline A $3 \times$ R 4 & $(30.41)$ & A $6 \times R 2$ & $(27.74)$ \\
\hline A $3 \times$ R 5 & $(30.26)$ & A $6 \times R 4$ & (26.13) \\
\hline A $3 \times$ R 6 & (51.78) & & \\
\hline A $3 \times R 7$ & (30.16) & & \\
\hline A $4 \times$ R 4 & (38.60) & & \\
\hline A $4 \times$ R 5 & (41.16) & & \\
\hline A $4 \times$ R 7 & (35.56) & & \\
\hline A $5 \times \mathrm{R} 1$ & $(30.32)$ & & \\
\hline A $5 \times R 2$ & (31.43) & & \\
\hline A $5 \times R 7$ & (32.13) & & \\
\hline A $6 \times R 3$ & (31.88) & & \\
\hline A $6 \times R 5$ & (36.07) & & \\
\hline A $6 \times$ R 6 & (39.98) & & \\
\hline A $6 \times$ R 7 & $(40.86)$ & & \\
\hline A $7 \times$ R 1 & (37.02) & & \\
\hline A $7 \times$ R 2 & (46.76) & & \\
\hline A $7 \times R 3$ & (33.07) & & \\
\hline A $7 \times$ R 4 & (41.06) & & \\
\hline A $7 \times$ R 5 & (49.14) & & \\
\hline A $7 \times$ R 6 & (44.19) & & \\
\hline A $7 \times$ R 7 & $(50.11)$ & & \\
\hline A $4 \times$ R 4 & (38.60) & & \\
\hline & Check & & \\
\hline
\end{tabular}


Table.6 Seven top ranking high oleic acid crosses showing SSR banding pattern at $749 \mathrm{bp}$ in sunflower

\begin{tabular}{|c|c|c|c|c|c|c|}
\hline $\begin{array}{l}\text { Sl. } \\
\text { No }\end{array}$ & $\begin{array}{l}\text { Derived } \\
\text { Crosses }\end{array}$ & $\begin{array}{l}\text { Oleic } \\
\text { acid } \\
(\%)\end{array}$ & $\begin{array}{c}\text { Yield } \\
\text { per } \\
\text { plant (g) }\end{array}$ & $\begin{array}{c}\text { Oil } \\
\text { content } \\
(\%)\end{array}$ & $\begin{array}{c}\text { SSR } \\
\text { banding } \\
\text { pattern }\end{array}$ & $\begin{array}{l}\text { Parental combination with } \\
\text { oleic proportion }\end{array}$ \\
\hline 1 & A $1 \times \mathrm{R} 4$ & 82.02 & 42.05 & 38.75 & 749 bp & $\mathrm{HO}(63.00) \times \mathrm{HO}(85.21)$ \\
\hline 2 & A $2 \times R 2$ & 81.29 & 45.43 & 27.00 & 749 bp & HO (74.02) x LO (26.47) \\
\hline 3 & A $4 \times R 2$ & 77.50 & 35.65 & 37.75 & 749 bp & HO (79.30) x LO (26.47) \\
\hline 4 & A $1 \times R 5$ & 66.19 & 31.50 & 35.00 & 749 bp & $\mathrm{HO}(63.00) \times \mathrm{HO}(66.24)$ \\
\hline 5 & A $2 \times R 4$ & 65.30 & 33.60 & 30.05 & 749 bp & $\mathrm{HO}(74.02) \times \mathrm{HO}(85.21)$ \\
\hline 6 & A $2 \times R 7$ & 60.93 & 39.05 & 36.90 & 749 bp & $\mathrm{HO}(74.02) \times \mathrm{HO}(77.61)$ \\
\hline 7 & A $4 \times$ R 6 & 60.37 & 22.85 & 33.75 & 749 bp & $\mathrm{HO}(79.30)$ x $\mathrm{HO}(68.92)$ \\
\hline
\end{tabular}

Note: HO - High oleic, LO - Low oleic

They have also become extremely popular markers for phylogenetic analysis adding new dimensions to the evolutionary theories. The development of these markers over the last two decades has provided easy, fast and automated assistance to scientists and breeders.

\section{Fatty acid analysis}

Fatty acid composition of sunflower in particular and other oil seed crop in general, are influenced by temperature, mainly regulating the ratio of oleic and linoleic acid (Garaces et al., 1989). Similarly, seed oil concentration is sensitive to environmental conditions during the grain filling period (Androde and Ferreiro, 1996). Low temperature leads to the reduction in oil yield and seed oil concentration occurred in sunflower and noted that decrease in photoperiod has a negative effect both on seed growth rate, seed oil quality and seed oil concentration in sunflower. Temperature effects would be more important during early seed filling and reduction in oleic acid concentration at the end (Merrien et al., 1993). Breeding of novel and healthier sunflower oil types with improved oil quality for specific applications has received great attention by plant breeders. Improvement in oil quality has been achieved mainly by modifying the fatty acid composition of the oil (Knowles, 1983; Ivanov et al., 1988; Osorio et al., 1995; Fernández-Martínez et al., 1997; Salas et al., 2004; Seiler, 2004 and Fernández-Moya et al., 2005). Genetic variation of fatty acid composition in sunflower oil has been achieved through conventional breeding and mutagenesis (Fernández-Martínez et al., 2007). Because sunflower fatty acid composition varies with different temperatures during seed development, there has been interestin in developing both high linoleic and oleic types that are temperature insensitive (Knowles, 1983; Miller and Vick, 1999). High oleic lines derived from Pervenets have been shown to be stable under different temperature regimes (Fernández-Martínez et al., 1986). Increased concentrations of SFAs are necessary for applications in the food industry that requires plastic fats (for production of margarines and shortenings) without the need of hydrogenation. Oils with higher SFA contents would be naturally more stable than oil from traditional sunflower. A high level of stearic acid is preferred over other SFAs due to its neutral effect on serum lipoprotein cholesterol (Pearson, 1994). Fatty acid profile of seven CMS lines, seven restorer lines and 49 derived crosses along with check hybrid 
RSFH-1 was estimated by using gas chromatography. The results were obtained for four fatty acids viz., palmitic acid, stearic acid, oleic acid and linoleic acid along with total oil content (Table 3). A low level palmitic acid is preferred from human health point of view, in the present study the proportion of palmitic acid was low in CMS lines A 1 (5.33\%), A 2 (5.34\%), A 4 (5.30\%) and A $7(5.04 \%)$, in restorer lines the lowest recorded was R 4 (4.25\%), R 6 (4.9\%) and R $7(4.83 \%)$, while in 49 derived crosses, it ranged from 3.86 to 7.73 per cent. Among the top high oleic acid crosses it recorded very high proportion of palmitic acid which ranged from 3.86 to 7.02 per cent compare to the check hybrid (RSFH 1) linoleic acid genotypes (5.08\%) (Table 4). Stearic acid is categorized as saturated fatty acid, the higher concentrations is an undesirable oil quality characteristic. In case of CMS lines, the low proportion was recorded in A 4 (3.73\%), A 6 (4.95\%) and A 7 (3.38\%), in restorer lines it was lowest in R 1 (2.93\%), R 7 (3.48\%), R 6 (3.92\%) and R 2 (3.96\%). While in 49 derived crosses it recorded very low proportion from 2.92 to 5.45 per cent. Among top seven crosses it recorded high proportion which ranged from 2.92 to 4.15 per cent compare to the check hybrid (RSFH1) (3.04\%) (Table 4). One advantage of the sunflower oil is its higher degree of oxidative stability than oils low in oleic acid (Fullner et al., 1967), which is desirable for frying purposes, refining and, storage. From the nutritional point of view, a diet rich in monounsaturated fatty acids has been suggested to reduce cholesterol in blood plasma (Flagella et al., 2012), and thus decreasing the risk of heart disease. In particular, the fatty acid composition is known to differ between cultivars and with environmental conditions (Connor and Sadras, 1992). The oleic acid proportion in sunflower genotypes varies from 30 to 90 per cent and generally the genotypes have been classified into three classes viz., low oleic
(10-29\%), Mid oleic (30-59\%) and High oleic (60-90\%) (Lacombe and Bervillé, 2001, Pecureanu-Joita et al., 2005).

Oleic acid content is essentially influenced by temperature during seed development Fick (1984). In present study, three CMS lines viz., A $2(74.03 \%)$, A $4(79.30 \%)$ and A 7 $(60.33 \%)$, four restorer lines viz., $\mathrm{R} 4$ (85.21\%), R 5 (66.24\%), R 6 (68.92\%) and R $7(77.61 \%)$ exhibited high oleic acid content. Among derived crosses, three crosses were found to be significantly higher oleic acid content viz., A 1 x R 4 (82.02\%), A 2 x R 2 $(81.29 \%)$ and A 4 x R $2(78.64 \%)$ compared to check hybrid RSFH-1 (78.64\%) (Table 4.). In traditional sunflower oil, the linoleic acid content will be generally very high (60-70\%). But in high oleic acid sunflower genotypes the linoleic acid content will be less than 10.00 per cent. In this study two CMS lines showed 11.66 and 14.38 per cent in A 4 and A 2 respectively. In restorer lines $\mathrm{R} 4$ has very low linoleic acid $(6.32 \%)$ followed by $R$ 7 (14.04\%). Among derived crosses, three crosses exhibited very low proportion viz., A $1 \times$ R $1(9.32 \%)$, A $2 \times$ R $2(11.10 \%)$ and A 4 x R 2 (11.30\%) (Table 3). The chromatogram of fatty acid profile of high oleic crosses are given in Figure 1 and 2, low oleic acid in Figure 3 and 4 along with high oleic check hybrid in Figure 5.

\section{Molecular characterization of the parents and derived crosses using SSR markers}

Sunflower seed oil composition and especially oleic acid content, is highly influenced by environmental factors as the temperature and the amount of moisture in the soil (Lájara et al., 1990). In addition, high oleic acid genes show unstable expression for oleic acid content in different genetic backgrounds and therefore phenotypic selection for the high oleic acid trait could be difficult across different environments and 
seasons (Demurin and Škorić, 2000). DNA markers are not influenced by the environment and therefore selection based on markers linked to the high oleic acid trait will allow further advance in breeding for this character. Identifying molecular markers linked to the high oleic acid trait (HOA) that can be further used in marker-assisted selection (MAS) would greatly contribute in developing stable mid and high oleic acid breeding lines. In an effort to characterize sunflower breeding genotypes based on oleic acid level using a DNA based marker system (SSR) and chromatographic technique, several dominant polymorphisms were discovered at a molecular level and facilitated the selection of the ol gene among different breeding genotypes. Regarding High oleic acid breeding, Fick (1984) found that the high oleic character was determined by a codominant gene called Ol, whereas Urie (1985) described this gene as dominant. A second modificator gene (Ml) of $\mathrm{Ol}$ was detected as necessary for the character expression (Miller et al., 1987).

Later, three complementary genes O11, Ol2, Ol3 were described (Fernández-Martínez et al., (1989). Several studies demonstrated the importance of molecular markers in the genetic analysis of sunflower.

The development of molecular markers has largely contributed to the establishment of saturated molecular maps. A number of linkage maps using various molecular markers, including RFLP, RAPD, AFLP and SSR markers have been published for sunflower (Berry et al., 1995; Gentzbittel et al., 1995; Tang et al., 2002; Yu et al., 2003 and Rachid Al-Chaarani et al., 2004).

A total of five SSR markers were used to screen 14 parental lines, 49 derived crosses and check hybrid RSFH-1. The results revealed that, among five markers used only one marker, N1-3F/N1-3R, produced polymorphic amplicon differentiating high oleic and low oleic acid types in sunflower (Fig. 6 and 7). The high oleic associated amplicon was specific at $749 \mathrm{bp}$ for the parental lines CMS A 1, A 2, A 4 and A 7 and restorer lines R 4, R 5, R 6, R 7 and for seven derived crosses (A $1 \times \mathrm{R} 4$, A $1 \times \mathrm{R} 5$, A 2 x R 2, A $2 \times \mathrm{R} 4$, A $2 \times \mathrm{R} 7$, A $4 \times \mathrm{R} 2$, A $4 \times \mathrm{R}$ 6) (Fig.8). For mid oleic lines A 3, R 1, R 3 and 31 derived crosses and also low oleic acid lines A 5, A 6, R 2 and 11 derived crosses, the marker N1-3F depicted polymorphic amplicon at 500bp but not at 749bp (Fig. 9 and 10). While the other marker ORS-311 showed monomorphic bands for high oleic, mid oleic and low oleic acid for all seven CMS and seven restorer lines (Fig. 11). Parents and crosses showing high, mid and low oleic acid proportions in sunflower (Table 5). The amplicons obtained for seven top ranking high oleic acid crosses are presented (Table 6), this indicates the presence of high oleic acid.

The high oleic specific band at 749 bp was absent in 31 mid oleic and 11 low oleic acid crosses. Both the parental species and derived crosses were analyzed for polymorphism using five SSR markers, Berville et al., (2009) reported similar results by using the primer N1-3F to derive useful information about polymorphism, genetic relatedness and diversity. Finally, two high oleic acid sunflower hybrids $(>80 \%)$ has been identified and PCR analysis with a primer (N1-3F/N1$3 \mathrm{R})$ assess the polymorphism between high and low oleic acid sunflower genotypes, this primer can be used to identify high and low oleic sunflower genotypes carrying the pervenet mutation, however the characterized high oleic specific SSR (N1-3F/N1-3R) marker need to be validated in $\mathrm{F} 2$ population, for further selection of high oleic genotypes under multilocation trials to know the stability of oleic acid, yield and oil content. 


\section{Acknowledgments}

This research was supported by grants from Main Agricultural Research Station and University of Agricultural Sciences, Raichur, Karnataka, India. All authors thank AICRPSunflower MARS, UASR, UHSB and IIOR for infrastructure facilities.

\section{Conflict of interest}

All the author states that there is no conflict of interest.

\section{References}

Androde, and Ferreiro (1996) Variability and correlation studies in different newly developed sunflower heads. J. Agric. Res., 54 (2): 256-263.

Anonymous, (2014-15) Annual Report. Sunflower, Directorate of Oilseed Research, Hyderabad 10:15-16.

Berry, S.T., Leon, A.J., Hanfrey, C.C., Challis, P., Burkholz, A., Barnes, S.R., Rufener,n G.K., Lee, M. and Caligari, P.D.S (1995) Molecular marker analysis of Helianthus annuus L. II. Construction of an RFLP linkage map for cultivated sunflower. Theo. Appl. Genet., 91: 195-199.

Berville, A (2009) Oil composition variations. In Genetics, genomics and breeding of sunflower, Hu, J., Seiler, G. and Kole, C. (Eds.), Science Publisher., 65: 253277.

Connor, D.J. and Sadras, V.O (1992) Physiology of yield expression in sunflower. Field Crops Res., 30: 333389.

Cummins, D.G., Marion, J.E., Craigmiles, J.P. and Burns, R.E (1967) Oil content, fatty acid composition, and other agronomic characteristics of sunflower introductions. J. American Oil Chemists' Society., 44: 581-582.
Demarin, Y. and Škorić, D (2000) Unstable expression of $\mathrm{Ol}$ gene for high oleic acid content in sunflower seeds. In: Proceedings of the 14th International Sunflower Conference, Beijing, China. International Sunflower Association, Paris., 8:145-150.

Doyle, J.J. and Doyle, J.L (1990) Isolation of plant DNA fresh tissue. Focus (San Francisco, California)., 12: 13-15.

Fernández-Martínez, J., Jiménez-Ramírez, A., Domínquez-Giménez, J. and Alcántara, M (1986) Temperature effect on the oleic and linoleic acids of three genotypes in sunflower., Grasas y Aceites., 37: 236-331.

Fernández-Martínez, J.M., Mancha, M., Osorio, J. and Garcés, R (1997) Sunflower mutant containing high levels of palmitic acid in high oleic acid background. Euphytica., 97: 113-116.

Fernández-Martínez, J.M., Pérez-Vich, B., Velasco, L. and Domínguez, J (2007) Breeding for speciality oils types in sunflower. Helia., 30: 75-84.

Fernández-Moya, V., Martínez-Force, E. and Garcés, R 92005) Oils from improved high stearic acid sunflower seeds. J. Agric and Food Chem., 53: 5326- 5330.

Fick, G.N. and Miller, J.F (1989) Sunflower breeding. In: Sunflower technology and production, Agronomy Monograph no 35. Schneiter, A.A. (Ed.). American Society of Agronomy Inc., Crop Science Society of America Inc., Soil Science Society of America Inc., Wisconsin, USA., 234: 395-439.

Flagella, Z., Rotunno, T., Tarantino, E., Di Caterina, R. and De Caro, A (2012) Changes in seed yield and oil fatty acid composition of high oleic sunflower (Helianthus annuus L.) hybrids in relation to the sowing date and the water regime. European J. Agron., 17: 221-230. 
Garcés, R., Sarmiento, C. and Mancha, M (1989) Temperature regulation of oleate desaturase in sunflower (Helianthus annuus L.) seeds Planta., 186: 461-465.

Gentzbittel, L., Vear, F., Zhang, Y.-X., Berville, A. and Nicolas, P (1995) Development of a consensus RFLP linkage map of cultivated sunflower (Helianthus annuus L.). Theo. Appl. Genet., 90: 1079-1086.

Ghadge, S. V. and Raheman, H (2005) Biodiesel production from mahua (Madhuca indica) oil having high free fatty acids. Biomass and Bioenergy., 28: 601-605.

Giriraj, K. and G. Nagaraj (2003) A high oleic acid Sunflower genotype. J. Oilseeds Res., 20(1): 172-173.

Gupta, M.K (2002) Sunflower oil. In: Vegetable oils in food technology: Composition, properties and uses. Gunstone, F.D. (Ed.). Blackwell Publishing Ltd. CRC Press LLC, USA, Canada., 22: 128-156.

Harwood, J (1996) Recent advances in the biosynthesis of plant fatty acids: A review. Biochimica et Biophysica Acta., 1301: 7-56.

Kalia, R.K., M.K. Rai, S. Kalia, R. Singh, A.K. Dhawan (2011) Microsatellite markers: an overview of the recent progress in plants. Euphytica., 177:309334.

Knowles, P.F (1983) Genetics and breeding of oilseed crops. Economic Botany., 37: 423-433.

Lacombe, S. and Bervillé, A (2001) A dominant mutation for high oleic acid content in sunflower (Helianthus annuus L.) seed oil is genetically linked to a single oleate desaturase RFLP locus. Mol. Breeding., 8: 129-137.

Lacombe, S., Souyris, I. and Bervillé, A (2009) An insertion of oleate desaturase homologous sequence silences via siRNA the functional gene leading to high oleic acid content in sunflower seed oil. Molecular Genetics and Genomics., 281: 43-54.

Lajara, J.R., Díaz, U. and Díaz-Quidiello, R (1990) Definite influence of location and climatic conditions on the fatty acid composition of sunflower seed oil. J. American Oil Chemists' Society., 67: 618-623.

Lu, G., Hu, X. and Bidney, D.L (2007) Sunflower. In: Biotechnology in Agriculture and Forestry. Volume 61, Transgenic Crops VI. Pua, E.C. and Davey, M.R. (Eds.). Springer-Verlag Berlin, Heidelberg., 24: 39-58.

Merrien, L.I., Pike, O.A., Ogden, L.V. and Dunn, M.L (2008) Oxidative stability of conventional and high oleic vegetable oils with added antioxidants. Journal of the American Oil Chemists' Society., 85: 771-776.

Miller, J. F., Zimmerman, D. C. and Vick B. A (1987) Genetic control of high oleic content in sunflower oil. Crop Sci., 27: 923-926.

Miller, J.F. and Vick, B.A (1999) Inheritance of reduced stearic and palmitic acid content in sunflower seed oil. Crop Sci., 39: 364-367.

Nagarathna, T. K., Anusha M. S. and Shadakshari Y. G (2010) Molecular marker Mediated Characterization of Sunflower (Helianthus annuus L.) Genotypes for High Oleic Acid. National Seminar on Innovative Biotechnology and Nanotechnology., 10:14-17.

Osorio, J., Fernández-Martínez, J.M., Mancha, M. and Garcés, R (1995) Mutant sunflower with high concentration in saturated fatty acid in the oil. Crop Sci., 35: 739-742.

Pearson, T.A (1994) Stearic acid and cardiovascular disease-answers and questions. American Journal of Clinical Nutrition., 60: 1017-1072 
Pecureanu-Joita, M., Stanciu, D., Petcu, E., Raranciuc, S. and Sorega, I (2005) Sunflower genotypes with high oleic acid content. Romanian Agric. Res., 22:23-26.

Rachid Al-Charaani, G., Gentzbittel, L., Huang, X. and Sarrafi, A (2004) Genotypic variation and identification of QTLs for agronomic traits using AFLP and SSR markers in RILs of sunflower (Helianthus annuus L.). Theo. Appl. Genet., 109: 1353-1360.

Salas, J.J., Martínez-Force, E. and Garcés, R (2004) Biochemical characterization of a high palmitoleic acid Helianthus annuus mutant. Plant Physiol and Biochem., 42: 373-381.

Seiler, G.J (2004) Wild Helianthus annuus, a potential source of reduced palmitic and stearic fatty acids in sunflower oil. Helia, 27: 55-62.

Simpson, B.W., McLeod, C.M. and George, D.L (1985) Selection for high linoleic acid content in sunflower (Helianthus annuus L.). Australian Journal of Experimental Agriculture, 29: 233-239.

Singh, S.P., Zhou, X.-R., Liu, Q., Stymne, S., Green, A.G (2005) Metabolic engineering of new fatty acids in plants. Curr. Opin. Plant Biology 8:197-203.

Skoric, D., S. Jocic, Z. Sakac, and N. Lecic (2008) Genetic possibilities for altering sunflower oil quality to obtain novel oils. Can. J. Physiol. Pharmacol, 86: 17.

Soldatov, K.I. (1976) Chemical mutagenesis in sunflower breeding. In: Proceedings of the 7th International Sunflower Conference, Krasnodar, USSR. International Sunflower Association, Vlaardingen, The Netherlands., 352357.

Spooner, D., R. Van Treuren and M.C. De Vicente (2005) Molecular Marker for Genebank Management. Technical Bulletin Number10. IPGRI, Rome., 127.

Tang, S. J.-K. Yu, M.B. Slabaugh, D.K. Shintani S.J. Knapp (2002) Simple sequence repeat map of the sunflower genome., Theor Appl Genet., 105:11241136.

Urie, A.L (1985) Inheritance of high oleic acid in sunflower. Crop Sci., 25: 986989.

Varshney, R.K., A. Graner and M.E. Sorrells (2005) Genic microsatellite markers in plants: features and applications. TRENDS in Biotechnology., 23 (1) 4855.

WHO (2003) Codex alimentarius commission, www.codexalimentarius.org

Yu, J.-K., Tang, S., Slabaugh, M.B., Heesacker, A., Cole, G., Herring, M., Soper, J., Han, F., Chu, W.-C., Webb, D.M., Thompson, L., Edwards, K.J., Berry, S., Leon, A.J., Grondona, M., Olungu, C., Maes, N. and Knapp, S.J (2003) Towards a saturated molecular genetic linkage map for cultivated sunflower. Crop Sci., 43: 367-387.

\section{How to cite this article:}

Tilak, I.S., B. Kisan, I. Shanker Goud, Mahantesha, B.N. Naika, Ayyangouda Patil, Vikas Kulkarni, Kadirvel Palchamy and Praduman Yadav. 2018. Biochemical and Molecular Characterization of Parents and its Crosses for High Oleic Acid Content in Sunflower (Helianthus annuus L.). Int.J.Curr.Microbiol.App.Sci. 7(04): 2000-2020. doi: https://doi.org/10.20546/ijcmas.2018.704.231 